\title{
GEOMECHANICAL RESPONSE OF PERMAFROST-ASSOCIATED HYDRATE DEPOSITS TO DEPRESSURIZATION-INDUCED GAS PRODUCTION
}

\author{
J. Rutqvist ${ }^{1}{ }^{*}$, G.J. Moridis ${ }^{1}$, T. Grover ${ }^{2, \psi}$, T. Collett ${ }^{3}$ \\ ${ }^{1}$ Earth Sciences Division, Lawrence Berkeley National Laboratory, MS 90-1116, \\ Berkeley, CA 947 20, USA \\ ${ }^{2}$ Petroleum Engineering Department, Texas A\&M University, MS 3116, \\ Richardson Building, College Station, TX, 77843, USA \\ ${ }^{3}$ U.S. Geological Survey, Denver Federal Center, Box 25046, MS-939, Denver, \\ CO 80225, USA \\ * Corresponding author. Tel.: +1-510-486-5432, fax.: +1-510-486-5686 \\ e-mail address: jrutqvist@lbl.gov (J. Rutqvist) \\ $\boldsymbol{\psi}$ Now with StatoilHydro ASA, Technology and New Energy - Production \\ Technology, 4035 Stavanger, Norway
}




\section{ABSTRACT}

In this simulation study, we analyzed the geomechanical response during depressurization production from two known hydrate-bearing permafrost deposits: the Mallik (Northwest Territories, Canada) deposit and Mount Elbert (Alaska, USA) deposit. Gas was produced from these deposits at constant pressure using horizontal wells placed at the top of a hydrate layer (HL), located at a depth of about $900 \mathrm{~m}$ at the Mallik and $600 \mathrm{~m}$ at the Mount Elbert. The simulation results show that general thermodynamic and geomechanical responses are similar for the two sites, but with substantially higher production and more intensive geomechanical responses at the deeper Mallik deposit. The depressurization-induced dissociation begins at the well bore and then spreads laterally, mainly along the top of the HL. The depressurization results in an increased shear stress within the body of the receding hydrate and causes a vertical compaction of the reservoir. However, its effects are partially mitigated by the relatively stiff permafrost overburden, and compaction of the HL is limited to less than $0.4 \%$. The increased shear stress may lead to shear failure in the hydrate-free zone bounded by the HL overburden and the downward-receding upper dissociation interface. This zone undergoes complete hydrate dissociation, and the cohesive strength of the sediment is low. We determined that the likelihood of shear failure depends on the initial stress state as well as on the geomechanical properties of the reservoir. The Poisson's ratio of the hydratebearing formation is a particularly important parameter that determines whether the evolution of the reservoir stresses will increase or decrease the likelihood of shear failure. 


\section{NOMENCLATURE}

$k_{h, v} \quad$ Horizontal/vertical permeability $\left[\mathrm{m}^{2}\right]$

$E \quad$ Young's modulus of elasticity [Pa]

$P \quad$ Pressure $[\mathrm{Pa}]$

$P_{W} \quad$ Well pressure $[\mathrm{Pa}]$

$Q_{R, P}$ Gas production/release rate $\left[\mathrm{ST} \mathrm{\textrm {m } ^ { 3 } / \mathrm { s } ]}\right.$

$S_{H} \quad$ Hydrate saturation

$T$ Temperature $\left[{ }^{\circ} \mathrm{C}\right]$

$U_{Z} \quad$ Displacement $[\mathrm{m}]$

$V_{R, P}$ Released/produced gas volume [ST $\left.\mathrm{m}^{3}\right]$

$\varepsilon_{v} \quad$ Volumetric strain

$\varepsilon_{Z} \quad$ Vertical strain

$v$ Poisson's ratio

$\sigma_{v} \quad$ vertical stress $[\mathrm{Pa}]$

$\sigma_{H, h}$ Maximum and minimum compressive horizontal stresses [Pa]

$\sigma_{l, 2,3}$ maximum, intermediate and minimum compressive principal stresses $[\mathrm{Pa}]$ 


\section{INTRODUCTION}

\subsection{Background}

Hydrates are solid crystalline compounds in which small gas molecules (referred to as guests) are lodged within the lattices of ice crystals (called hosts). The dominant gas in natural hydrate accumulations is $\mathrm{CH}_{4}$. Hydrates are stable under conditions of low temperature $\mathrm{T}$ and high pressure $P$ in two different geologic settings: in permafrost and deep oceans.

The assessment of the global inventory of hydrate distribution in geologic media is in an embryonic state, and different estimates vary by as much as several orders of magnitude (Sloan and Koh, 2008). However, the scientific consensus is that the total amount of $\mathrm{CH}_{4}$ (and other hydrocarbons) trapped in hydrates is enormous, and easily exceeds the equivalent of all the known conventional oil and gas. The rapidly escalating global energy demand has forced the question of whether hydrates can be developed and exploited as a potential energy source. To address this issue, a significant international research effort has begun recently (Moridis et al., 2008). Of the three possible methods of hydrate dissociation (Makogon, 2007) for gas production (i.e., depressurization, thermal stimulation, and use of inhibitors), depressurization is considered to be the most effective and economically promising method (and probably the only viable alternative) for the commercial production of natural gas from hydrate deposits (Moridis and Reagan, 2007a, b; Collett, 2008a).

Among the serious technical challenges related to the issue of gas production from hydrates (Moridis et al., 2008a), geomechanical issues are particularly important, because they affect 
the integrity of the formation and well stability, and can by themselves prevent the exploitation of otherwise promising hydrate accumulations.

Hydrate deposits that are suitable targets for gas production often involve unconsolidated sediments characterized by limited shear strength. The dissociation of the solid hydrates (a strong cementing agent) during gas production can undermine the structural stability of hydrate-bearing sediments (HBS). This is further exacerbated by the evolution of expanding gas zones, the progressive transfer of loads from the hydrate to the sediments, and subsidence. Additionally, the depressurization of a hydrate deposit may lead to a more anisotropic stress field, potentially leading to shear failure within the dissociating hydrate accumulation. Thus, the potential geomechanical response of hydrate deposits, and their impact on the system flow behavior and resource recovery, needs to be carefully evaluated before commercial-scale gas production from permafrost deposits can be developed. This study focuses on this issue.

\subsection{Objective and approach}

The objective of this simulation study is to analyze the geomechanical response of two permafrost deposits under production, and to develop the first-ever first assessment of the impact of production on the likelihood of formation failure, and magnitude of reservoir compaction and ground settlement. The state of knowledge on the subject is embryonic at best, because the general dearth of information is compounded by the significant geomechanical complication of the "stiff" permafrost overburden. Although the geomechanical response of marine hydrate deposits with compressible overburdens has 
received some attention in the past (Kimoto et al., 2007; Rutqvist and Moridis, 2008), this analysis of permafrost systems is (to the best of our knowledge) the first study of its kind.

The two hydrate deposits investigated in this study are (a) the Mallik accumulation (Mackenzie Delta, Northwest Territories, Canada) and (b) the Mount Elbert deposit (North Slope, Alaska, USA). Both deposits have been, and still are, the site of past and present studies, from which a large body of information has been acquired. Thus, it is no exaggeration that these two deposits are probably among the best characterized.

The importance of these two deposits, and the reason for their selection for this analysis, stems from the likelihood of their being among the sites considered for the design, development, and execution of the first large-scale, long-term gas production test (Moridis et al., 2008a). The reasons for their suitability for such a long-term test include (a) the confirmed presence of hydrates at high saturations, (b) the occurrence of high-quality HBS, (c) site accessibility through proximity to infrastructure, and (d) site knowledge. This being the case, it is imperative to determine as early as possible if there are any geomechanical restrictions (or even barriers) to gas production from such permafrost hydrate deposits, and, should this be the case, to develop strategies to overcome them.

The numerical simulation studies discussed in this paper involve linking the TOUGH+ HYDRATE simulator (Moridis and Reagan, 2007a and b; Moridis et al., 2005 and 2008b) of hydrate behavior in geologic media with the FLAC3D (Itasca, 2006) commercial geomechanical code. In this simulation approach, the TOUGH+HYDRATE simulator solves 
governing equations related to hydraulic, thermal, and thermodynamic behavior in geological media containing gas hydrates. The FLAC3D is used to calculate geomechanical responses as a result of changes in pressure, temperature, and hydrate saturation. The FLAC3D code has built-in constitutive laws suitable for soil and rocks, including various elastoplastic laws for quasi-static yield and failure analysis, and viscoplastic constitutive laws for time dependent (creep) analysis, that could be used directly or modified for analysis of geomechanical behavior of hydrate bearing sediments. In the resulting coupled simulator, the two constituent simulators, TOUGH+HYDRATE and FLAC3D are linked through a coupled thermalhydrological-mechanical (THM) model of HBS. The basic couplings between hydrological and mechanical processes in the deformable porous media are considered through constitutive laws that define how changes in pressure, temperature, and hydrate saturation affect deformation and stress, and how changes in stress and strain affect fluid flow. The numerical approach, linking the processes and operation of the coupled codes, have been described in detail by Rutqvist and Moridis (2008) and Rutqvist et al. (2008) in their analysis of the geomechanical behavior of oceanic HBS.

The investigation approach involves the simulation of 5 years of continuous gas production at the two sites, using horizontal wells that were kept at a constant bottom-hole pressure $P_{W}=$ 2.7 MPa, i.e., slightly above the quadruple point in order to prevent the formation of ice in the reservoir. The geomechanical properties of the hydrate bearing sediments and the initial stress field are treated as perturbation parameters in the sensitivity analysis component of the study. This approach is dictated by the lack of site-specific data and uncertainties in the estimation of these parameters at the two sites. During this production period, we monitor the production 
performance, and the evolution of key thermodynamic and geomechanical parameters, and we also provide side-by-side comparison of the geomechanical responses at the two sites.

\section{DESCRIPTION OF THE STUDY SITES}

The discussion in this section follows closely the analyses of Dallimore et al. (1999), Dallimore and Collett (2005), and Collett (2008a), which are the most thorough treatises on the subject.

\subsection{The Mallik gas hydrate accumulation}

The Mallik field is probably the best-characterized gas hydrate accumulation in the world. It is located at the northeastern edge of Canada's Mackenzie Delta, within a sequence of Tertiary sediments in an area overlain by about $600 \mathrm{~m}$ of permafrost. Detailed geologic and engineering data on gas hydrates and associated sediments are available (Dallimore et al., 1999; Dallimore and Collett, 2005). Quantitative well-log determinations and core studies reveal at least 10 discrete gas hydrate layers exceeding $110 \mathrm{~m}$ in total thickness, from approximately 900 to $1,100 \mathrm{~m}$ depth. The gas hydrate intervals have high gas hydrate saturation values that, in some cases, exceed 80\% of the pore volume (Dallimore et al., 1999; Dallimore and Collett, 2005), with the estimates of the amount of trapped gas in the 1 to 10 trillion cubic meter (TCM) range (Osadetz and Chen, 2005). These attributes establish the Mallik field as one of the most concentrated gas hydrate reservoirs in the world.

Recognizing that the Mallik gas hydrate accumulation was an ideal site for a field test of gas

production from a natural gas hydrate, an international partnership was formed to carry out a 
production research program in 2002 (Dallimore and Collett, 2005). Field operations for the 2002 Mallik program were carried out during the winter of 2001/2002 and provided an extensive data set covering a wide spectrum of subjects related to natural hydrate deposits: geology, geophysics, geochemistry, microbiology, kinetics of gas hydrate dissociation, geomechanics, petrophysical, thermal and hydraulic properties, etc. The production testing included short duration, small-scale pressure drawdown tests and a 5-day thermal stimulation test. This testing allowed the calibration of several numerical models, the determination of important properties and parameters, and an assessment of the long-term production response of a gas hydrate accumulation (Dallimore and Collett, 2005).

\subsection{The Mount Elbert gas hydrate accumulation}

Studies of pressurized core samples, downhole logs, and production testing at the Northwest Eileen State-2 well (located in the northwest part of the Prudhoe Bay Field) provided the first direct confirmation of gas hydrates on the North Slope (where the Mount Elbert deposit is located) by identifying three hydrate-bearing stratigraphic units (Collett, 2008a, b; Lorenson et al., 2008). Based on downhole log data from an additional 50 wells in the same area, investigators indentified hydrate units in six laterally continuous sandstone and conglomerate. The volume of gas within this area is estimated to be about twice that of the known conventional gas in the Prudhoe Bay Field, ranging between 35 and 42 trillion cubic feet (TCF).

A collaborative project that aims to determine the viability of the North Slope hydrates as an energy source is currently in progress (Boswell et al., 2008). In 2007, a well was installed at 
an accumulation named the "Mount Elbert" prospect to acquire critical reservoir data needed to develop a longer-term production test program. The well was drilled through $590 \mathrm{~m}$ of permafrost to a depth of $915 \mathrm{~m}$ and achieved recovery of significant lengths of core of the hydrate intervals. These were used for subsequent investigations on the pore water geochemistry, microbiology, gas chemistry, petrophysical properties, and thermal and

physical properties. A flow test conducted in two sandy hydrate-bearing sections with high $S_{H}$ (60\% to $75 \%$ yielded gas in both tests) has provided one of the most comprehensive datasets yet compiled on a natural hydrate accumulation (Collett, 2008a).

Analysis of the data collected from the well will be used to support decisions on the advisability, site selection, well type and location, production method, and timing of the next phase of the project. This is currently envisioned as a long-term production test to determine the reservoir deliverability and the gas production potential of permafrost deposits under a variety of well design and operation scenarios.

\section{SIMULATED SYSTEM \& APPROACH}

Analysis of the geology of the two sites indicates that the HBS sequences at both Mallik and Mount Elbert are mainly composed of sand and weakly cemented sandstones with silt/shale interbeds, confined by nearly impermeable shale boundaries. As such, they are typical representatives of Class 3 deposits (Moridis and Reagan, 2007b).

\subsection{Geometry, boundaries and discretization}


The geometry of the rectangular 3D system (stencil) we consider in this study has a square cross section in the $x z$-plane and a side length of $800 \mathrm{~m}$. A horizontal well is placed at the top of the hydrate layer (HL) along the $x=400 \mathrm{~m}$ axis. Because of symmetry (a) along the $y$ axis and (b) about the $x=400 \mathrm{~m}$ axis, it suffices to simulate a 2D slice in $(x, z)$ that has a unit thickness along the 3rd dimension $(\Delta y=1 \mathrm{~m})$, includes the entire system profile (from the surface to $30 \mathrm{~m}$ below the HL into the underburden) along the $z$ coordinate, and is $\Delta x=400 \mathrm{~m}$ long along the $x$ coordinate (Figure 1 and Table 1$)$. The $(x, z)$ plane of the simulated domain and the location of the horizontal well are shown in the lower part of Figure 1. Because of symmetry, there is no flow of fluids and heat through the lateral boundaries (vertical sides) of the domain. For the same reason, we impose a restriction of zero-displacement normal to these boundary surfaces. The top boundary, representing the ground surface, is kept at constant $T$ and $P$, but is allowed to move. The bottom boundary (placed at a depth of $30 \mathrm{~m}$ below the HL) has a fixed $P$ and $T$, and a restriction of zero-displacement along the $z$-axis, i.e., normal to the boundary.

In the case of the Mallik deposit, the 2D domain was discretized in $120 \times 100=12,000$ elements in $(x, z)$, resulting in 36,000 equations when the equilibrium dissociation option was invoked. The discretization of the 2D domain in the Mount Elbert cases resulted in $120 \times 93=$ 11,160 elements in $(x, z)$ and 34,800 equations. In both cases, discretization along the $x$-axis is logarithmic (with an initial $\Delta x=0.1 \mathrm{~m}$ ), and the vertical discretization is variable. The fine discretization of $\Delta z=0.25 \mathrm{~m}$ in the HL allows an accurate description of the dynamic processes occurring there. 


\subsection{Initial conditions}

Table 2 presents the initial conditions at the base of the HL at the two sites. The initial $P, T$ and stresses are higher at the Mallik deposit because of a greater depth. The initial $S_{H}$ is about $75 \%$ at the Mallik deposit, and 65\% at the Mount Elbert accumulation. The initial stress gradients for both sites are based on site geomechanical investigations at the Mallik area (McLellan et al., 2005a). The vertical stress gradient is about $\sigma_{V}=19.6 \mathrm{MPa} / \mathrm{km}$ corresponding to a bulk density of the overlying permafrost zone of about $2,000 \mathrm{~kg} / \mathrm{m}^{3}$. Based on estimates by McLellan et al. (2005a), the horizontal stresses $\sigma_{H}=\sigma_{h}$ in the region range between 13.2 to $18.8 \mathrm{MPa} / \mathrm{km}$, i.e., they are lower than the vertical stresses.

Our approach in this study involves a set of two simulations: (1) a reference (base) case that is based on an average horizontal stress gradient of $15 \mathrm{MPa} / \mathrm{km}$ (i.e., $\sigma_{H}=\sigma_{h}=0.77 \sigma_{V}$ ), and (2) a bounding case adopting the lower bound of the horizontal stress gradient in the calculations, i.e., $\sigma_{H}=\sigma_{h}=0.67 \sigma_{V}=13.2 \mathrm{MPa} / \mathrm{km}$. This lower $\sigma_{H}$ bound corresponds to a geologic medium that is near critically stressed for shear, i.e., with pre-existing fractures and with the unconsolidated sand near its frictional limit. This is consistent with the observed pattern of natural fractures at the Mallik deposit, which indicates that the conjugate shear fractures dip about $60^{\circ}$ (McLellan et al., 2005b).

\subsection{Hydraulic and thermal properties}


Table 3 presents some of the main input hydrological and thermal properties for Mallik and Mount Elbert deposits. The hydraulic and thermal properties for the Mallik site are based on the laboratory and field data published in Dallimore et al. (1999) and Dallimore and Collett (2005). The hydraulic and thermal properties used for the Mount Elbert study were those used in the code comparison study of Anderson et al. (2008). These, were derived using information gleaned from geophysical well logs, as well as flow parameters estimated by history-matching the data from a short-term open-hole depressurization test. As can be seen in Table 3, the hydraulic and thermal properties are similar at the two sites.

\subsection{Geomechanical properties}

The geomechanical properties of the reservoir and overlying rock are of particular importance, but they are also the most uncertain. Some information on the geomechanical properties at the Mallik site can be deduced from geophysical surveys conducted during past research activities (Collett et al., 2005; McLellan et al., 2005b; Mi et al., 1999). For example, Figure 2 presents vertical profiles of compressional- and shear-wave velocity from Vertical Seismic Profiling (VSP) and sonic logs at Mallik (Mi et al., 1999). The sonic velocities are functions of dynamic elastic properties and can be used to estimate the magnitude of, and variability in, the static elastic and strength properties (Zoback, 2007). Using compressional and shear-wave velocity logs from the Mallik 5L-38 well and the Gaussmann (1951) equations, estimates of the dynamic elastic properties have been obtained (Collett et al., 2005). The Mallik 5L-38 sonic log data show that compressional-wave velocity increases from about 2,000 m/s to about 2,500 m/s when transitioning from pure sand to the HL, whereas the shear-wave velocity increases from 1,000 to $1,500 \mathrm{~m} / \mathrm{s}$. The resulting dynamic 
Poisson's ratio is about 0.4 both inside and outside the HL. The Young's modulus $E$ is about $5 \mathrm{GPa}$ outside the HL, and increases to about $15 \mathrm{GPa}$ within the HL. However, values of static, rather than dynamic, properties are needed in a coupled reservoir-geomechanical analysis of stress and strain changes induced by hydrate dissociation.

The results of Winters et al. (1999 and 2007) and Uchida et al. (2005) from a few laboratory experiments on samples from the Mallik site may be used to estimate the static strength and elastic properties. As expected, the values of the geomechanical properties deduced from these laboratory experiments are up to several orders of magnitude lower than those obtained from the sonic well logs at Mallik. On the other hand, the strength and stiffness values of the Mallik samples (Winters et al., 1999 and 2007; Uchida et al., 2005) are similar to those of Toyoura Sand estimated from laboratory studies by Masui et al. (2005), and which have been used by Rutqvist and Moridis (2008) and Rutqvist et al. (2008) to study the geomechanical behavior of oceanic hydrate bearing sediments undergoing dissociation.

Adopting these properties implies that the static modulus is about $1 / 10$ of the dynamic modulus, and that the static Poisson's ratio is significantly lower than that derived from sonic data. A reasonable value of static Poisson's ratio for sand or weakly cemented sandstone should be less than about 0.25, averaging around 0.15 (Spencer et al. 1994; Zoback, 2007), whereas it has been observed that sonic logs consistently overestimate Poisson's ratio, even in gas saturated sands (Dvorkin, 2006). The Poisson's ratio determined from static laboratory tests on artificial hydrate-bearing Toyoura Sand ranged from 0.1 to 0.2 , and averaged 0.15 independently of the hydrate saturation (Masui et al., 2005). Recently, Masui et al. (2008) 
conducted additional laboratory studies on natural hydrate bearing cores recovered from eastern Nakai Trough, Japan, and found a consistent Poisson's ratio between natural and artificial hydrate-bearing samples.

For the aforementioned reasons, in our computations we adopted the two sets (static and dynamic) of geomechanical properties listed in Table 4. The static properties were based on the experimental data on Toyoura sand (Masui et al., 2005 and 2008), and are consistent with the limited laboratory data from Mallik. The dynamic properties were estimated from compressional- and shear-wave velocity logs using geophysical standard theory and empirical equations (e.g., Gaussmann, 1951; Zoback, 2007). The parameters describing the mechanical properties of the Toyoura sediment are corrected for pore-filling solid content (hydrate and ice). According to the experimental results of Masui et al. (2005; 2008), we assumed that certain mechanical properties (bulk and shear moduli, and cohesion) increase linearly with hydrate saturation. For example, the cohesion varies from $0.5 \mathrm{MPa}$ at $0 \%$ hydrate saturation to an extrapolated $2.0 \mathrm{MPa}$ at $100 \%$ hydrate saturation, and the bulk modulus varies from 95 MPa at $0 \%$ hydrate saturation to an extrapolated $670 \mathrm{MPa}$ at $100 \%$ (Table 4). These linear relationships match the laboratory data quite well over the range of hydrate content relevant to this study. For example, Figure 3 shows a good match of the adopted model to triaxial shear strength data over the 0 to $70 \% S_{H}$ range. Moreover, following the experimental results of Masui et al. (2005), the friction angle and Poisson's ratio are considered independent of the hydrate saturation $S_{H}$. A dilation angle of $10^{\circ}$ is adopted in a nonassociated Mohr-Coulomb model. We assume that the dilation angle is independent of hydrate content, although the experimental results by Masui (2005) indicate a slight increase in the dilation angle with hydrate content. 
We used the same mechanical properties for the Mallik and Mount Elbert cases, which is a reasonable approach, given the relative similarities of the geological settings of these sites. In the reference case we use the mechanical properties derived from the laboratory experiments on Toyoura Sand (Masui et al., 2005), which, to the our knowledge, represent the most complete, systematic, and relevant data set on the static mechanical properties of a hydratebearing sand. These properties are reasonable, considering the known differences between dynamic and static mechanical properties, and are consistent with the results from the few static geomechanical experiments conducted on samples from the Mallik deposit. For comparison, we conduct an additional simulation using the dynamic properties to show the importance of complementing sonic log data with systematic laboratory testing.

\section{SIMULATION RESULTS}

Because the HL is hydraulically confined by shales, depressurization is rapid and effective, leading to fast hydrate dissociation and considerable cooling during the 5 years of production considered in this study. The constant $P_{W}$ at the well and the low effective permeability of the HBS creates a pressure disturbance characterized by a sharp front coinciding with the dissociation front. This front moves rapidly outward from the well, and it extends laterally along the $x$-axis after first reaching the bottom of the HL. Because depressurization is localized (being confined to the limited volume of dissociated or rapidly dissociating medium between the well and the front), most mechanical deformations and stress changes reach maximum levels very early, i.e., within the first year of production. 
Thus, instead of gradual geomechanical changes that occur over a large reservoir volume, production from hydrates is uniquely characterized by maximum changes that are arrived at early (and then remain practically unchanged) within a small volume that centers around the well and expands slowly.

\subsection{Production Performance}

Figure 4 shows the evolution of (a) the volumetric release rate $Q_{R}$ of the hydrate-originating $\mathrm{CH}_{4}$ into the reservoir, and (b) the volumetric rate $Q_{P}$ of $\mathrm{CH}_{4}$ production, both summed over the entire $800 \mathrm{~m}$ length of the horizontal well. The $Q_{R}$ and $Q_{P}$ patterns are quite similar (as expected, being both Class 3 deposits in similar geologic settings and with similar properties), and they are both consistent with the behavior of such deposits (Moridis and Reagan, 2007b), i.e., with $Q_{P}$ only slightly lower than $Q_{R}$. The Mount Elbert deposit is slower to respond because of its lower temperature (Table 2), and is considerably less productive than the Mallik deposit. Thus, at $t=5$ years, $Q_{P}=0.7 \mathrm{ST} \mathrm{m} 3 / \mathrm{s}(=2.15 \mathrm{MMSCFD})$ at the Mallik deposit, but $Q_{P}=0.11 \mathrm{ST} \mathrm{m} 3 / \mathrm{s}(=0.34 \mathrm{MMSCFD})$ at Mount Elbert.

The superiority of the Mallik deposit as a production target is confirmed by the cumulative volumes of released $\left(V_{R}\right)$ and produced $\left(V_{P}\right)$ gas in Figure 5, which show the total Mallik production $V_{P}=9 \times 107 \mathrm{ST} \mathrm{m}{ }^{3}(=3.2 \mathrm{BCF})$ dwarfing the $V_{P}=1.53 \mathrm{ST} \mathrm{m}^{3}(=0.54 \mathrm{BCF})$ from Mount Elbert. In addition to its higher temperature, another reason for the superior performance of the Mallik formation is the larger HL thickness (Table 2). Figure 5 shows 
very small volumes of free gas in the reservoir, as is typical in production from Class 3 deposits (Moridis and Reagan, 2007b).

Figure 4 shows that initially $Q_{R}$ and $Q_{P}$ increase rapidly, and then they begin oscillating around a plateau. An increasing trend is observed in the $Q_{R}$ and $Q_{P}$ of the Mallik deposit, though not in the Mount Elbert one. It is not possible to know if these trends will persist later because only a small fraction of the total mass is destroyed at the end of the 5-year production period (Figure 6).

\subsection{Evolution of thermodynamic state}

Figures 7 and 8 show the spatial distributions of $P, T$, and $S_{H}$ at $t=3$ yrs in the Mallik and Mount Elbert deposits, respectively. Despite the diffusive nature of $P$ (which is transmitted even when flow is inhibited), a sharp front is easily detected in both figures at a location that roughly matches that of the dissociation front, and is confirmed by the corresponding minimum $T$ (because of the endothermic dissociation reaction) at the same location. Note that dissociation occurs mainly at the top of the HL, but the HL bottom is also beginning to show faint signs of dissociation. Because of reduced dissociation in the colder Mount Elbert deposit, the edge of the dissociation front reaches only $120 \mathrm{~m}$ from the well at $t=3 \mathrm{yrs}$, compared to $280 \mathrm{~m}$ in the Mount Elbert deposit.

Figure 9 shows the temporal evolution of $P, T$, and $S_{H}$ at the top of the HL and at $x=10 \mathrm{~m}$ from the production well. Note that (a) the hydrate is destroyed within a short time (10 days 
in the Mallik deposit, 30 days in the Mount Elbert one), and (b) after the hydrate exhaustion, $P$ (which controls the geomechanical behavior) remains practically constant. This supports the earlier discussion that geomechanical changes reach their maximum level early in time.

\subsection{Evolution of the geomechanical regime}

The main geomechanical responses are associated with the depressurization of the hydrate deposit, that causing an increase in vertical effective stress, that, in turn, results in increased shear stress and vertical compaction of the reservoir.

Figure 10 shows the evolution of effective and total principal stresses for the base case, i.e., with static reservoir properties and an initial horizontal stress gradient of $15 \mathrm{MPa} / \mathrm{km}$ (i.e., $\sigma_{H}$ $\left.=\sigma_{h}=0.77 \sigma_{V}\right)$. The figure shows that the effective principal stresses in the reservoir change quickly proportionally to the fluid $P$ responses shown in Figure 9. Overall, production (and the corresponding depressurization) tends to increase the shear stress in the reservoir, which is proportional to the difference between the maximum and minimum principal stresses. The total maximum compressive principal stress $\sigma_{1}$ is approximately constant throughout the simulation, as determined by the weight of the overburden rock. The intermediate and minimum compressive principal stresses $\sigma_{2}$ and $\sigma_{3}$ are horizontal and change as a result of poroelastic stressing during depressurization. The effective maximum principal stress $\sigma_{1}^{\prime}=\sigma_{l}$

- $P$, is vertical and increases proportionally to the reduction in fluid pressure. The effective intermediate and minimum compressive principal stresses $\sigma_{2}^{\prime}=\sigma_{2}-P$ and $\sigma_{3}^{\prime}=\sigma_{3}-P$ are 
horizontal and increase much less, because much of the pressure decrease is offset by an increase in total stresses $\sigma_{2}$ and $\sigma_{3}$. The magnitudes of stress changes are higher at Mallik as a result of a more substantial depressurization at that site.

Figure 11 presents the path of the maximum and minimum principal effective stresses for three different mechanical conditions. The figure shows that the effective principal stress state moves into failure (shaded area) only in the case of static mechanical properties and a low initial horizontal stress (i.e., an initial horizontal stress gradient of $13.2 \mathrm{MPa} / \mathrm{km}$, and $\sigma_{H}=\sigma_{h}$ $\left.=0.67 \sigma_{V}\right)$. If the initial horizontal stress is higher, the initial effective stress state is much further away from failure and never moves into failure during depressurization. For static properties, the stress state moves along a slope $\Delta \sigma_{1}^{\prime} / \Delta \sigma_{3}^{\prime}=5.5$, whereas for dynamic properties, the stress state moves along an initial slope of $\Delta \sigma_{1}^{\prime} / \Delta \sigma_{3}^{\prime}=1.5$. Using the assumption of a thin and laterally extensive reservoir, it can be shown that the slope $\Delta \sigma_{1}^{\prime} / \Delta \sigma_{3}^{\prime}$ can be determined from the Poisson's ratio. For the static Poisson's ratio, $v=0.15$ the slope can be calculated analytically as $\Delta \sigma^{\prime} l \Delta \sigma_{3}^{\prime}=5.5$, whereas for the sonic Poisson's ratio $v=0.4$, the slope is $\Delta \sigma_{1}^{\prime} / \Delta \sigma_{3}^{\prime}=1.5$. In the numerical simulation result shown in Figure 11, the stress path does not follow these slopes precisely, because the numerical results are affected by changes in elastic properties due to hydrate dissociation, and by thermal stresses. However, the results show that the Poisson's ratio of the reservoir rock is an important parameter, one that determines whether reservoir stresses during depressurization will increase or decrease the likelihood of shear failure. 
Figure 12 presents the evolution of the maximum compressive effective stress and strength at the same monitoring point located about $10 \mathrm{~m}$ from the production well. At both Mallik and Mount Elbert deposits, the initial (pre-production) maximum stress is much less than the compressive strength. For example, at Mallik, the initial compressive strength is $14.5 \mathrm{MPa}$ for a hydrate saturation of $75 \%$, whereas the maximum compressive effective stress is about 9 MPa (Figure 12a). During the depressurization, the maximum compressive strength remains much larger than the stress until the hydrate starts to dissociate. At the Mallik site, the dissociation and weakening of the sediment implies that failure starts at about 10 days, and thereafter the maximum compressive effective stress that the sediment can sustain is limited by the strength of the sediment (Figure 12a). At Mount Elbert, the dissociation is slower, due to a smaller depressurization at that site, but shear failure is triggered after about 2 months (Figure 12b).

Figures 13 and 14 show the distribution of volumetric strain $\varepsilon_{V}$ after 1 and 3 years of production. The largest volumetric strain develops within the dissociated zone at the top of the HL. Thus, in this zone there is a more substantial compaction as a result of sediment softening. The maximum volumetric strain $\varepsilon_{v}$ is $0.6 \%$ at Mallik (Figure 13) and $0.3 \%$ at Mount Elbert (Figure 14). At Mallik, the local vertical strain is a factor of two larger than at Mount Elbert, because of a factor of two larger pressure drop $\Delta P$.

Figure 15 presents the time evolution of the vertical settlement at the ground surface and at the top of the reservoir, and the resulting average vertical compaction strain $\varepsilon_{Z}$ of the HL. For 
both the Mallik and Mount Elbert deposits, $\varepsilon_{Z}$ is restricted by the relatively stiff permafrost overburden. As a result, the vertical settlement $U_{Z}$ of the ground surface is somewhat smaller than the corresponding $U_{Z}$ at the reservoir, especially at early times. The stiffening effect of the permafrost overburden diminishes as the depressurization of the deposit becomes more extensive after several years of production. Overall, for the adopted mechanical properties, $\varepsilon_{Z}$ $<0.4 \%$ and $U_{Z}=6 \mathrm{~cm}$ at Mallik. The corresponding $\varepsilon_{Z}$ and $U_{Z}$ are smaller at Mount Elbert, as a result of a smaller depressurization and a thinner deposit.

\section{DISCUSSION}

The static elastic properties, such as the Young's modulus and Poisson's ratio, determine the magnitude of settlement as well as the reservoir stress path and the likelihood for shear failure during depressurization of the HL. A good understanding of the in situ static properties requires a combination of field surveys, such as sonic logs, and systematic laboratory testing of hydrate bearing samples. In particular, more laboratory data are needed to constrain static elastic properties (Young's modulus and Poisson's ratio) as well as strength properties (e.g. cohesion and coefficient of friction) and how these properties vary with hydrate content, confining stress, and strain rate. The important differences between dynamic and static properties have already been discussed in Section 3.4. Concerning strain rate and confining pressure, it should be pointed out that the strength and elastic properties adopted in this study (from Masui et al., 2005), were determined at a strain rate of $0.1 \% / \mathrm{min}$. Moreover, the adopted Young's moduli and its dependency on hydrate saturation were determined at a

confining stress of $1 \mathrm{MPa}$. Recently, Masui et al. (2008) conducted additional experiments to 
determine the influence of strain rate, and Miyazaki et al. (2008) presented results for increasing confining pressure. They found the Poisson's ratio to be insensitive to changes in hydrate saturation and independent of strain rates, whereas shear strength and in particular Young's modulus decreases with strain rate. With the decreasing strain rate from $0.1 \% / \mathrm{min}$ to $0.001 \% / \mathrm{min}$, the shear strength was reduced approximately $30 \%$ and the elastic modulus by $60 \%$. During depressurization in the field, the hydrate-bearing sand is exposed to a much slower strain rate, and an elevated shear stress will be sustained for years, indicating that the strength and elastic modulus adopted in this study may be higher than the real in situ properties. On the other hand, the confining effective stresses at the Mallik and the Mount Elbert sites are estimated to be about 3 to $5 \mathrm{MPa}$ (see $\sigma_{2}^{\prime}$ and $\sigma_{3}^{\prime}$ in Figure 10), which indicate that the adopted Young's modulus determined at $1 \mathrm{MPa}$ would be lower than the real in situ modulus. As a result, the decrease in Young's modulus with strain rate may be offset by an increase in confining stress. Thus, we conclude that our adopted properties are reasonable, whereas more sophisticated models that include dependency of strain rate and modulus can be readily implemented and applied once more data becomes available. Adopting such a model would not change the conclusions or significantly change the simulation results in this modeling study, but may have an impact on the exact magnitude of settlement and extent of shear failure zone.

In this study, considering in situ stress conditions and mechanical properties at the Mallik and the Mount Elbert sites, we found that depressurization and the associated increased shear stress may lead to shear failure in the zone of production-induced hydrate dissociation near the well bore and upper part of the HL (see zone of hydrate dissociation in Figures 7c and 8c). 
Because this zone undergoes complete hydrate dissociation, the cohesive strength of the sediment becomes low enough to initiate plastic yield and shear failure. At the moment, we can only speculate about how such shear failure could affect gas production. The shear failure facilitates shear deformations, leading to an enhanced compaction of the reservoir and possibly resulting in shear-induced changes in permeability. However, shearing may either enhance or destroy formation permeability. Moreover, shear yielding of weakly cemented sand may break bonds between particles, leading to enhanced sand production. Recent gas hydrate production tests at Mallik (2007 and 2008) showed that sand production is a major issue during depressurization production—an issue that will require engineering measures such as sand screen to assure continuous water and gas flow (Numazawa et al., 2008).

In the presence of pre-existing natural fractures in the HL, depressurization-induced shear stress may lead to shear reactivation of the pre-existing fractures, which in turn may affect the production performance. The observed pattern of natural fractures at the Mallik deposit indicated conjugate fractures dipping about $60^{\circ}$ (McLellan et al., 2005b). In the present normal faulting stress regime $\left(\sigma_{v}>\sigma_{H} \approx \sigma_{h}\right)$, our analysis of the stress path evolution shows that these fractures could be reactivated if they are initially near critically stressed, i.e., on the verge of shear failure. Evidence from fractured rock masses has shown a good correlation between maximum in situ shear stress and water conducting fractures (e.g., Barton et al., 1995). Moreover, a shear over effective normal stress ratio $\left(\tau / \sigma^{\prime}\right)$ exceeding 0.6 on a fracture has been observed as the lower-limit value for hydraulic conducting fractures and their correlation with maximum shear stress (Barton et al. 1995). This finding indicates that over the long term, a shear over effective normal stress ratio $\left(\tau / \sigma^{\prime}\right)$ exceeding 0.6 on a fracture can 
lead to enhanced permeability. Investigations with a Formation-Micro Imager (FMI) tool at the Mallik showed that natural fractures were open and likely water filled, whereas recovered cores indicate partially mineralized fracture surfaces. For the lower-range stress, the lower bound of horizontal stress gradient is adopted in the calculations, i.e., $\sigma_{H}=\sigma_{h}=0.67 \sigma_{V}=13.2$ $\mathrm{MPa} / \mathrm{km}$, the initial effective shear over effective normal stress ratio $\left(\tau / \sigma^{\prime}\right)$ on steely dipping fractures would be close to or exceed 0.6. Consequently, a small perturbation in the stress field during depressurization could induce shear reactivation. In this case, the depressurization induces a substantial increase in shear stress that could induce shearing along fractures, which may dilate and extend, leading to increased fracture permeability, connectivity, and surface area for dissociation of the hydrate-bearing formation. The likelihood and potential benefits of such fracture shear reactivation will be the subject of future studies.

\section{CONCLUSIONS}

In our study of depressurization-induced gas production from the Mallik and Mount Elbert Class 3 hydrate deposits, using horizontal wells at the HL top, and kept at a constant bottomhole pressure, we reach the following conclusions:

(1) The depressurization causes preferential hydrate dissociation that proceeds mainly along the HL top.

(2) The depressurization of the hydrate reservoir results in vertical compaction of the reservoir and in increased shear stress within the reservoir. The magnitude of vertical compaction and shear stress depends on the magnitude of depressurization and the elastic properties of the reservoir and overlying formations. 
(3) The calculated $\varepsilon_{Z}$ is within $0.5 \%$, and the estimated $U_{Z}<6 \mathrm{~cm}$. Of the two deposits, Mallik has the largest $\varepsilon_{Z}$ and $U_{Z}$ because of larger depressurization and a thicker HL.

(4) Depressurization increases the effective shear stress because the vertical effective stress increases much more than the horizontal effective stress. At both Mallik and Mount Elbert, the higher shear stress may lead to shear failure in the zone of hydrate dissociation between the HL overburden and the downward-receding upper dissociation interface.

(5) The likelihood of shear failure is strongly dependent on the initial stress state and on the elastic properties of the reservoir. In particular, the Poisson's ratio $v$ of the HBS is an important parameter determining the effective stress path during depressurization. When a dynamic $v=0.4$ (from sonic logs) is used, the predicted effective stress state always diverges from shear failure during depressurization. When a static $v=0.15$ (a reasonable estimate for unconsolidated sand) is used, the effective stress state will tend towards shear failure, but may not reach it, depending on the initial stress state.

Overall, the estimated vertical compaction at these two sites is rather limited (within $0.4 \%$ ), partially mitigated by the relatively stiff permafrost overburden. Moreover, the vertical compaction is expected to be relatively uniform, leading to uniform settlements of the ground surface. The potential shear failure within the reservoir might be a more serious issue, because this could affect the gas production in terms of permeability and sand production. At any site, the coupled thermodynamic and geomechanical approach used in this study can be applied for optimizing production, while minimizing the likelihood for such unwanted geomechanical responses. 


\section{ACKNOWLEDGMENTS}

We are grateful for reviews by Matthew Reagan and Dan Hawkes at the Lawrence Berkeley

National Laboratory, which substantially improved this paper. This work was supported by the Assistant Secretary for Fossil Energy, Office of Natural Gas and Petroleum Technology, through the National Energy Technology Laboratory, under the U.S. Department of Energy Contract No. DE-AC02-05CH11231.

\section{REFERENCES}

Anderson, B.J., Wilder J.W., Kurihara, M., White, M.D., Moridis, G.J., Wilson, S.J., PooladiDarvish, M., Masuda, Y., Collett, T.S., Hunter, R.B., Narita, H., Rose K., Boswell R., 2008. Analysis of modular dynamic formation test results from the "Mount Elbert" stratigraphic test well, Milne Point, Alaska. In: Proceedings of the 6th International Conference on Gas Hydrates (ICGH 2008), Vancouver, British Columbia, Canada, July 6-10.

Boswell, R., Hunter, R., Collett, T., Diggert, S., Hancock, S., Weeks, M., 2008. Investigation of gas hydrate-bearing sandstone reservoirs at the "Mount Elbert" stratigraphic test well, Milne Point, Alaska. Proceedings of the 6th International Conference on Gas Hydrates (ICGH 2008), Vancouver, British Columbia, Canada, July 6-10, 2008.

Collett, T.S., 2008a. Artic gas hydrate energy assessment studies. The Artic Energy Summit. Anchorage, Alaska, 2007-2008.

Collett, T.S., 2008b. Geologic and engineering controls on the production of permafrostassociated gas hydrated accumulations. Proceedings of the 6th International Conference on Gas Hydrates (ICGH 2008), Vancouver, British Columbia, Canada, July 6-10, 2008.

Collett, T.S., Lewis, R.E., Dallimore, S.R., 2005. JAPEX/JNOC/GSC et al. Mallik 5L-38 gas hydrate production research well downhole well-log and core montages. In: Dallimore S.R., Collett T.S., editors. Scientific Results from the Mallik 2002 Gas Hydrate Production Research Well Program, Mackenzie Delta, Northwest Territories, Canada. Geological Survey of Canada, Bulletin 585.

Dallimore, S.R., Uchida, T., Collett, T.S., 1999. Scientific Results from the JAPEX/JNOC/GSC Mallik 2L-38 Gas Hydrate Research Well, Mackenzie Delta, Northwest Territories, Canada. Geological Survey of Canada Bulletin 544.

Dallimore, S.R., Collett, T.S., 2005. Scientific results from the Mallik 2002 gas hydrate production research well program, Mackenzie Delta, Northwest Territories, Canada. Geological Survey of Canada, Bulletin 585.

Dvorkin, J., 2006. Can gas sand have a large Poisson's ratio? SEG Expanded Abstracts 25, 1908: DOI:10.1190/1.2369900.

Gaussmann, F., 1951. Uber die elastizitat poroser medien. (Elasticity of porous media). Vierteljahrsschrift der Naturforschenden Gesselschaft in Zurich, 96, 1-23. 
Itasca., 2006. FLAC3D Version 3.1-User's Guide. Third Edition. Itasca Consulting Group, Inc. Minneapolis, Minnesota.

Kimoto, S., Oka F., Fushita, T., Fujiwaki, M., 2007. A chemo-thermo-mechanically coupled numerical simulation of the subsurface ground deformations due to methane hydrate dissociation. Computers and Geotechnics 34,216-228.

Lorenson, T.D., Collett, T.S., Hunter, R., 2008. Preliminary assessment of hydrocarbon gas resources from the Mt. Elbert No. 1 gas hydrate test well, Milne Pt. Alaska. Proceedings of the 6th International Conference on Gas Hydrates (ICGH 2008), Vancouver, British Columbia, Canada, July 6-10, 2008.

Makogon, Y.F., 2007. Hydrates of Hydrocarbons. Penn Well Publishing Co. Tulsa, OK. 237pp.

Masui, A., Haneda, H., Ogata, Y., Aoki, K., 2005. The effect of saturation degree of methane hydrate on the shear strength of synthetic methane hydrate sediments. In: Proceedings of the 5th International Conference on Gas Hydrates (ICGH 2005), Trondheim, Norway, June 12-16.

Masui, A., Miyazaki, K., Haneda, H., Ogata, Y., Aoki, K., 2008. Mechanical characteristics of natural and artificial gas hydrate bearing sediments. Proceedings of the 6th International Conference on Gas Hydrates (ICGH 2008), Vancouver, British Columbia, Canada, July 6-10, 2008.

McLellan, P.J., Gillen, K.P., Podetz, C.G., Dallimore, S.R., Inoue, T., Hancock, S.H., $2005 a$. In situ stresses in the Mallik area. In: Dallimore S.R., Collett T.S., editors. Scientific Results from the Mallik 2002 Gas Hydrate Production Research Well Program, Mackenzie Delta, Northwest Territories, Canada. Geological Survey of Canada, Bulletin 585.

McLellan, P.J., Gillen, K.P., Podetz, C.G., Dallimore, S.R., 2005b. Characteristics of natural fractures in the JAPEX/JNOC/GCS et al. Mallik 5L-38 gas hydrate production research well. In: Dallimore S.R., Collett T.S., editors. Scientific Results from the Mallik 2002 Gas Hydrate Production Research Well Program, Mackenzie Delta, Northwest Territories, Canada. Geological Survey of Canada, Bulletin 585.

Mi, Y., Sakai, A., Walia, R., Hyndman, R.D., Dallimore, S.R., 1999. Vertical seismic profiling and seismic properties of gas hydrate in an Arctic well. CREWES Project Research Report, volume 11, Calgary, Alberta, Department of Geology and Geophysics, Univ. of Calgary, Calgary.

Moridis, G.J., Kowalsky, M.B., Pruess, K., 2005. Depressurization-induced gas production from class 1 hydrate deposits, SPE REE 10, 458-481.

Moridis, G.J., Reagan, M.T., 2007a. Gas Production From Oceanic Class 2 Hydrate Accumulations. OTC 18866, 2007 Offshore Technology Conference, Houston, Texas, U.S.A., 30 April-3 May 2007.

Moridis, G.J., Reagan, M.T., 2007b. Strategies for Gas Production From Oceanic Class 3 Hydrate Accumulations, OTC 18865, 2007 Offshore Technology Conference, Houston, Texas, 30 April - 3 May 2007.

Moridis, G.J,, Collett, T.S., Boswell, R., Kurihara, M., Reagan, M.T., Koh, C., Sloan, E.D., 2008. Toward production from gas hydrates: Current status, assessment of resources, and simulation-based evaluation of technology and potential. SPE 114163, 2008 SPE Unconventional Reservoirs Conference, Keystone, Colorado, U.S.A., 10-12 February. 
Moridis, G.J., Kowalsky, M., Pruess, K., 2008. TOUGH+HYDRATE v 1.0 User's manual, Report LBNL-149E, Berkeley, CA: Lawrence Berkeley National Laboratory - Earth Sciences Division, 2008.

Numasawa, M., Yamamoto, K., Yasuda M., Fujii, T., Fujii K., 2008. Objectives and operation overview of the 2007 JOGMEC/NRCA/AURORA Mallik 2L-38 Gas hydrate production test. Proceedings of the 6th International Conference on Gas Hydrates (ICGH 2008), Vancouver, British Columbia, Canada, July 6-10, 2008.

Osadetz, K.G., Chen, Z., 2005. A re-examination of Beaufort Sea - Mackenzie Delta Basin gas hydrate resource potential using a petroleum system approach. Proceedings of the Fifth International Conference on Gas Hydrates, Trondheim, Norway, June 13-16, 2005.

Rutqvist, J., Moridis, G.J. 2008. Numerical studies on the geomechanical stability of hydratebearing sediments. OTC 18860, SPEJ, accepted July 2008.

Rutqvist, J., Grover, T., Moridis, G.J., 2008. Coupled hydrological, thermal and geomechanical analysis of wellbore stability in hydrate-bearing sediments. OTC 19572, 2008 Offshore Technology Conference, Houston, Texas, 4 May - 8 May 2008.

Sloan, E.D., Koh, C., 2008. Clathrate Hydrates of Natural Gases. 3rd Edition. Taylor and Francis, Inc., Boca Raton, FL. 721pp.

Spencer, J.W., Cates, M.E., Thompson, D.D., 1994. Frame moduli of unconsolidated sands and sandstones. Geophysics, 59, 1352-1361.

Uchida, T., Uchida, T., Kato, A., Sasaki, H., Kono, F., Takeya, S., 2005. Physical properties of natural gas hydrate and associated gas-hydrate-bearing sediments in the JAPEX/JNOC/GSC et al. Mallik 5L-38 gas hydrate production research well. In: Dallimore S.R., Collett T.S., editors. Scientific Results from the Mallik 2002 Gas Hydrate Production Research Well Program, Mackenzie Delta, Northwest Territories, Canada. Geological Survey of Canada, Bulletin 585.

Winters, W.J., Dallimore, S.R., Collett, T.S., Katsube, T.J., Jenner, K.A., Cranston, R.E., Wright, J.F., Nixon, F.M., Uchida, T., 1999. Physical properties of sediments for the JAPEX/JNOC/GSC. Mallik 2L-38 gas hydrate research well. Geological Survey of Canada, Bulletin 544.

Winters, W.J., Waite, W.F., Mason, D.H., 2007. Methane gas hydrate effect on sediment acoustic and strength properties. Journal of Petroleum Science and Engineering. 56, $127-$ 135.

Zoback, M., 2007. Reservoir Geomechanics. Cambridge University Press. 237pp. 


\section{Tables}

Table 1. Model dimensions for Mallik and Mount Elbert (see Figure 1).

\begin{tabular}{|l|c|c|}
\hline \multicolumn{1}{|c|}{ Dimensions } & Mallik & Mount Elbert \\
\hline $\begin{array}{l}\text { Permafrost zone, } \\
\mathrm{L}_{\mathrm{PF}}(\mathrm{m})\end{array}$ & 606 & 590 \\
\hline $\begin{array}{l}\text { Unfrozen overburden } \\
\text { thickness, } \mathrm{L}_{\mathrm{o}}(\mathrm{m})\end{array}$ & 300 & 60 \\
\hline HL depth $(\mathrm{m})$ & 906 to 930 & 650 to 661.25 \\
\hline $\begin{array}{l}\text { HL thickness, } \\
\mathrm{L}_{\mathrm{HBS}}(\mathrm{m})\end{array}$ & 24 & 11.25 \\
\hline Underburden thickness $(\mathrm{m})$ & 30 & 30 \\
\hline Well spacing $(\mathrm{m})$ & 800 & 800 \\
\hline
\end{tabular}

Table 2. Initial conditions at the base of the HL in the Mallik and Mount Elbert deposits.

\begin{tabular}{|l|c|c|}
\hline \multicolumn{1}{|c|}{ Parameter } & Mallik & Mount Elbert \\
\hline Pressure $(\mathrm{MPa})$ & $\approx 9.1$ & $\approx 6.6$ \\
\hline Temperature $\left({ }^{\circ} \mathrm{C}\right)$ & $\approx 7.2$ & $\approx 2.8$ \\
\hline Hydrate saturation $(\%)$ & 75 & 65 \\
\hline Vertical stress $(\mathrm{MPa})$ & $\approx 17.6$ & $\approx 12.7$ \\
\hline Horizontal stress $(\mathrm{MPa})$ & $\approx 13.6$ & $\approx 9.7$ \\
\hline
\end{tabular}


Table 3. Hydrological and thermal properties for Mallik and Mount Elbert.

\begin{tabular}{|l|c|c|}
\hline \multicolumn{1}{|c|}{ Property } & Mallik & Mount Elbert \\
\hline Permeability $(\mathrm{mD})$ & $\begin{array}{l}\mathrm{k}_{\mathrm{h}}=1200 \\
\mathrm{k}_{\mathrm{h}} / \mathrm{k}_{\mathrm{v}}=10\end{array}$ & $\begin{array}{l}\mathrm{k}_{\mathrm{h}}=1000 \\
\mathrm{k}_{\mathrm{h}} / \mathrm{k}_{\mathrm{v}}=10\end{array}$ \\
\hline Porosity $(\%)$ & 37 & 2650 \\
\hline $\begin{array}{l}\text { Grain density } \\
\left(\mathrm{kg} / \mathrm{m}^{3}\right)\end{array}$ & 2650 & 3.1 \\
\hline $\begin{array}{l}\text { Wet thermal } \\
\text { conductivity }(\mathrm{W} / \mathrm{m} / \mathrm{K})\end{array}$ & 2.24 & 1 \\
\hline $\begin{array}{l}\text { Dry thermal } \\
\text { conductivity }(\mathrm{W} / \mathrm{m} / \mathrm{K})\end{array}$ & 1 & 1000 \\
\hline Grain Specific Heat $(\mathrm{J} / \mathrm{kg} / \mathrm{K})$ & 1000 & \\
\hline
\end{tabular}

Table 4. Two sets (static and dynamic) of input geomechanical properties used in the study of the Mallik and Mount Elbert deposits.

\begin{tabular}{|l|c|c|c|}
\hline \multicolumn{1}{|c|}{ Property } & Hydrate Saturation & Static Properties & Dynamic properties \\
\hline \multirow{3}{*}{ Cohesion $C_{m}(\mathrm{MPa})$} & $S_{H}=0$ & 0.5 & 5 \\
\cline { 2 - 4 } & $S_{H}=1$ & 2.0 & 20 \\
\hline \multirow{2}{*}{ Friction angle $\left(^{\circ}\right)$} & $S_{H}=0$ & 30 & 30 \\
\hline \multirow{3}{*}{ Dilation angle $\left(^{\circ}\right)$} & $S_{H}=1$ & 30 & 30 \\
\hline \multirow{3}{*}{ Young's Modulus $E(\mathrm{GPa})$} & $S_{H}=0$ & 10 & 10 \\
\cline { 2 - 4 } & $S_{H}=1$ & 10 & 10 \\
\hline \multirow{2}{*}{ Poisson's ratio $v$} & $S_{H}=0$ & 0.5 & 18 \\
\hline & $S_{H}=1$ & 1.8 & 0.4 \\
\cline { 2 - 4 } & $S_{H}=0$ & 0.15 & 0.4 \\
\hline
\end{tabular}


Figures

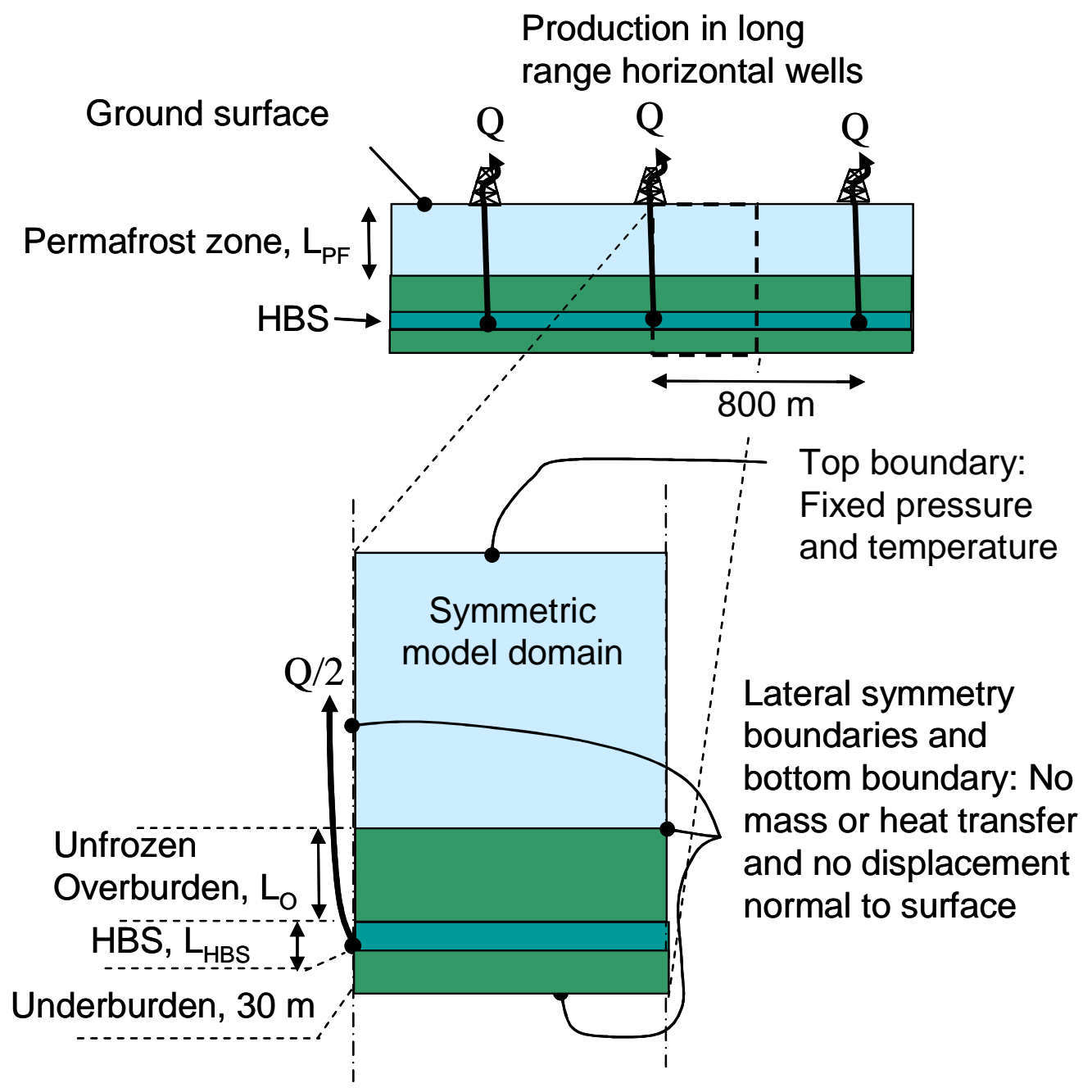

Figure 1. Simulation domain geometry. 


\section{$P$ and $S$ velocities}

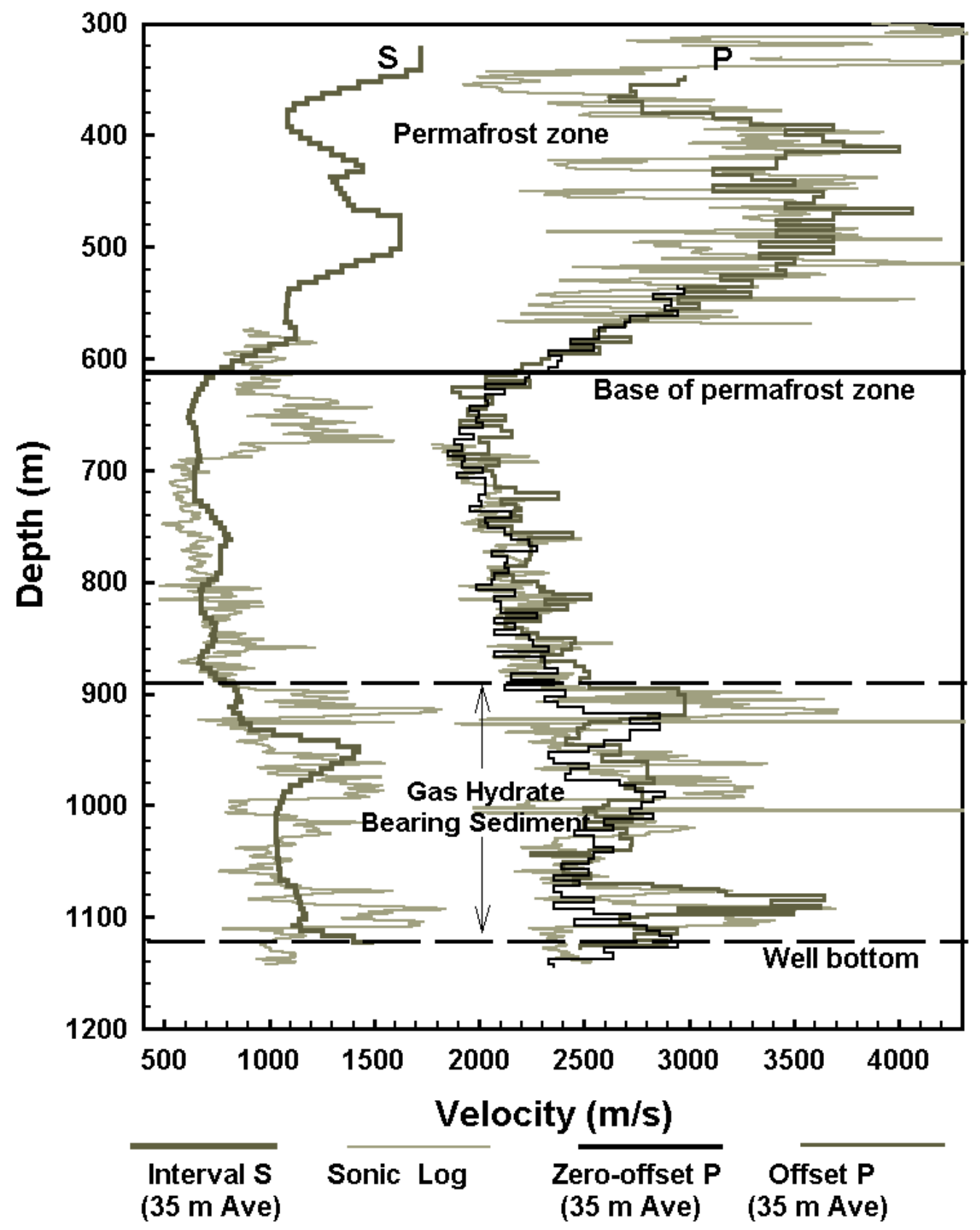

Figure 2. Vertical profiles of compressional- and shear-wave velocity derived from VSP and sonic log analysis at the Mallik well 2L-38 (Mi et al., 1999). 


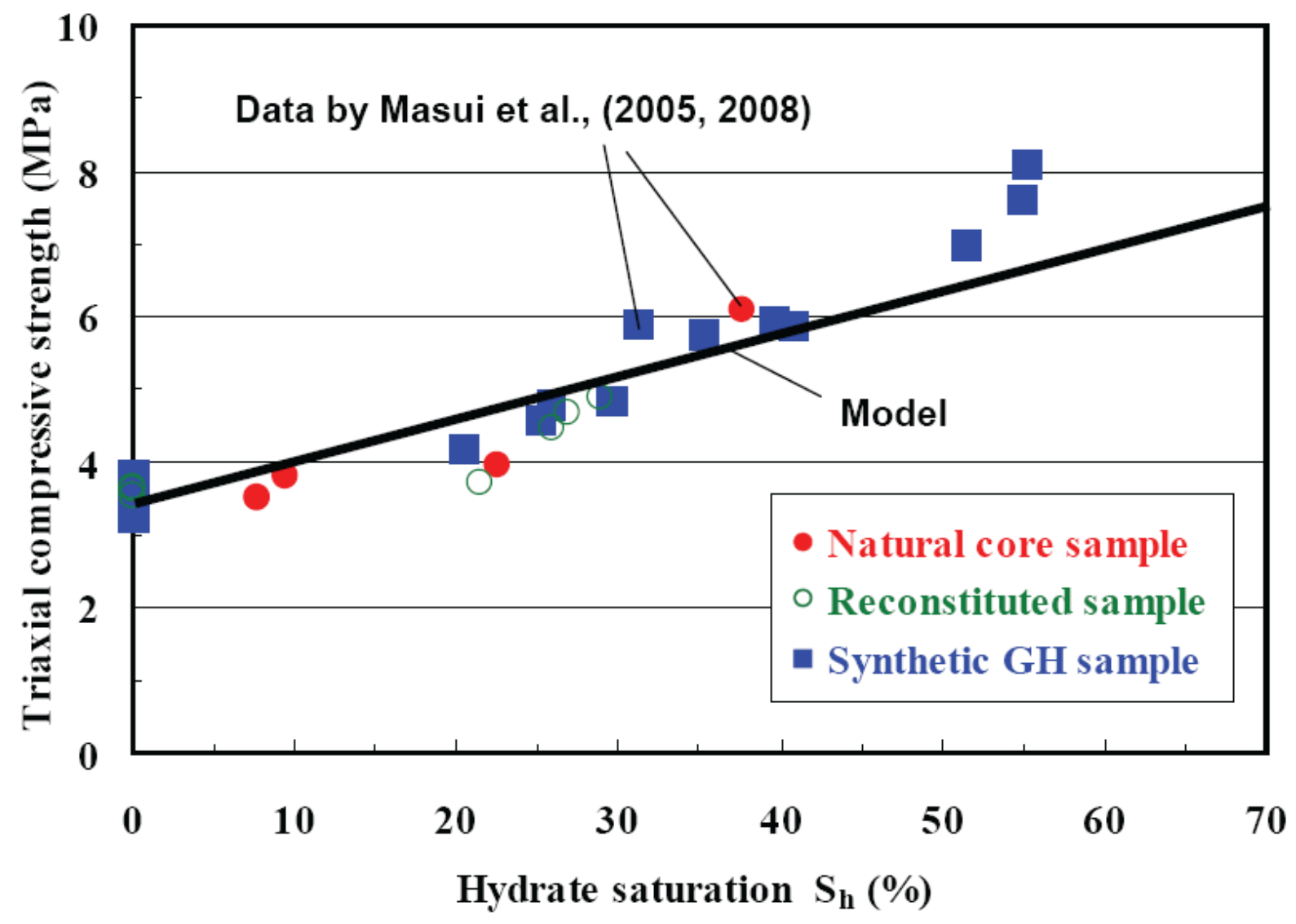

Figure 3. Laboratory data of triaxial compressive strength from Masui et al. (2005) and (2008) of artificial and natural samples of hydrate-bearing sand and linear dependency of strength and hydrate saturation adopted in this study. 

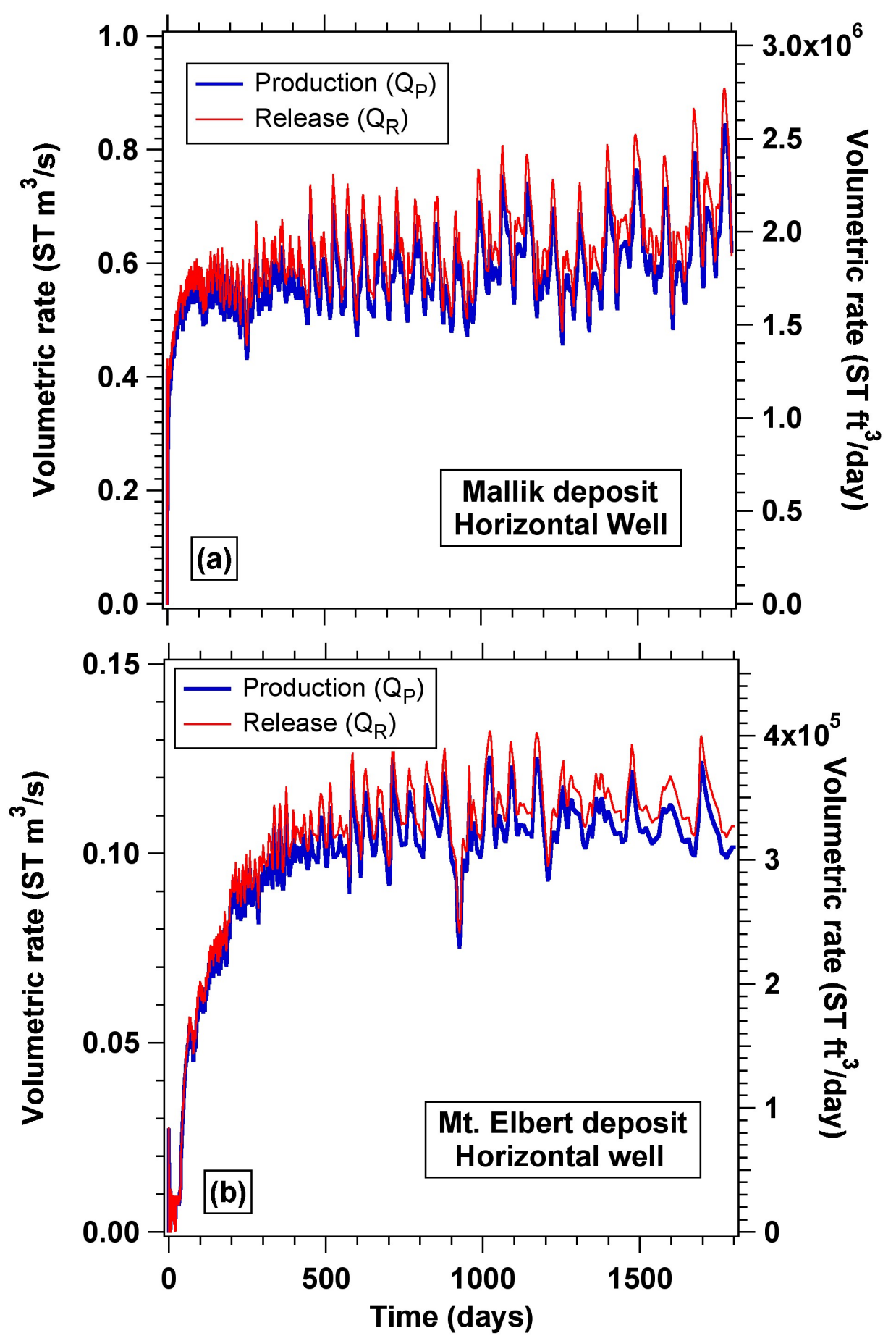

Figure 4. Gas release and production rates from the (a) Mallik and (b) Mount Elbert deposits. 

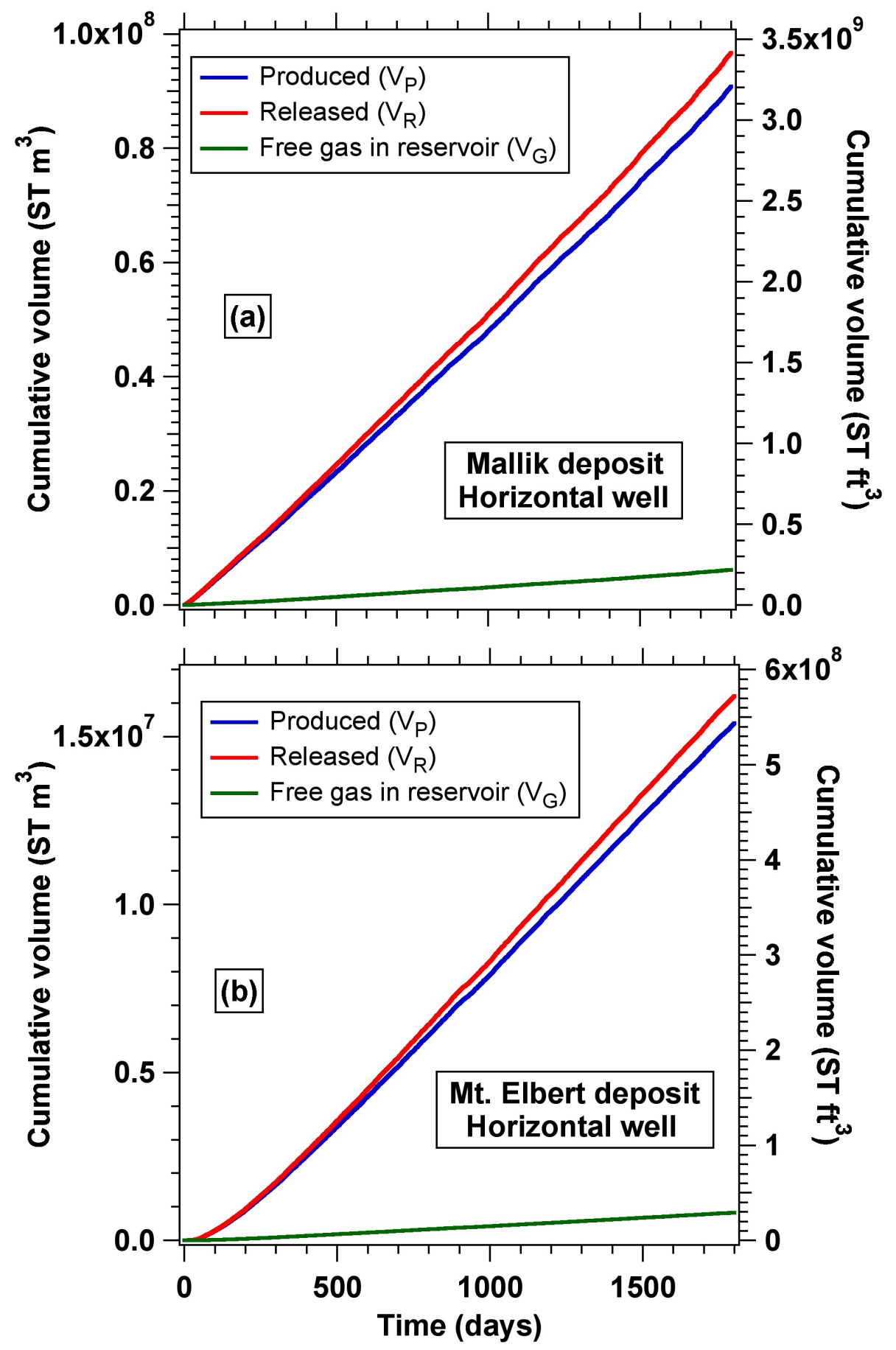

Figure 5. Cumulative volumes of released, produced, and free gas in the (a) Mallik and (b) Mount Elbert deposits. 


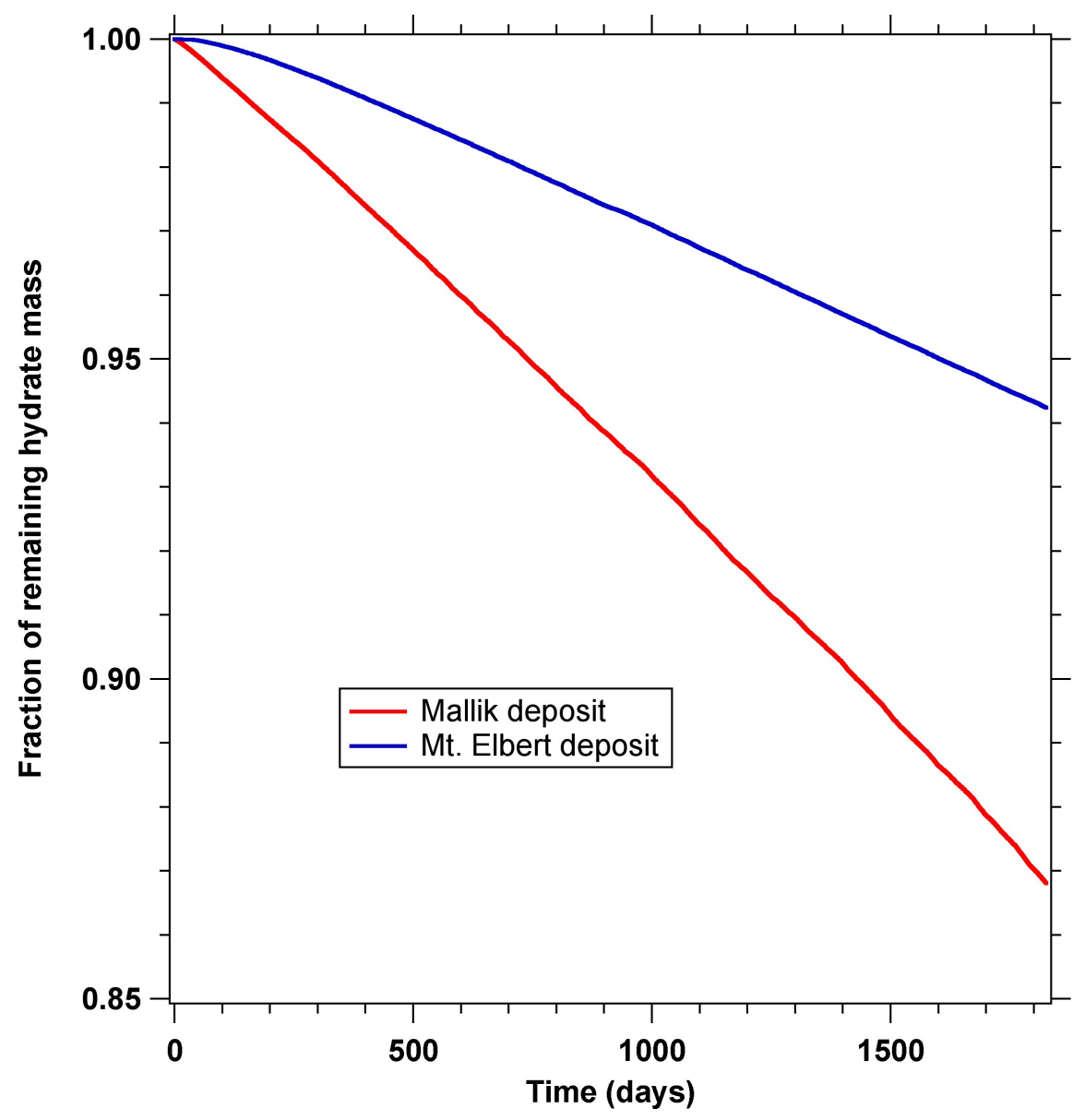

Figure 6. Remaining hydrate in the deposits. 

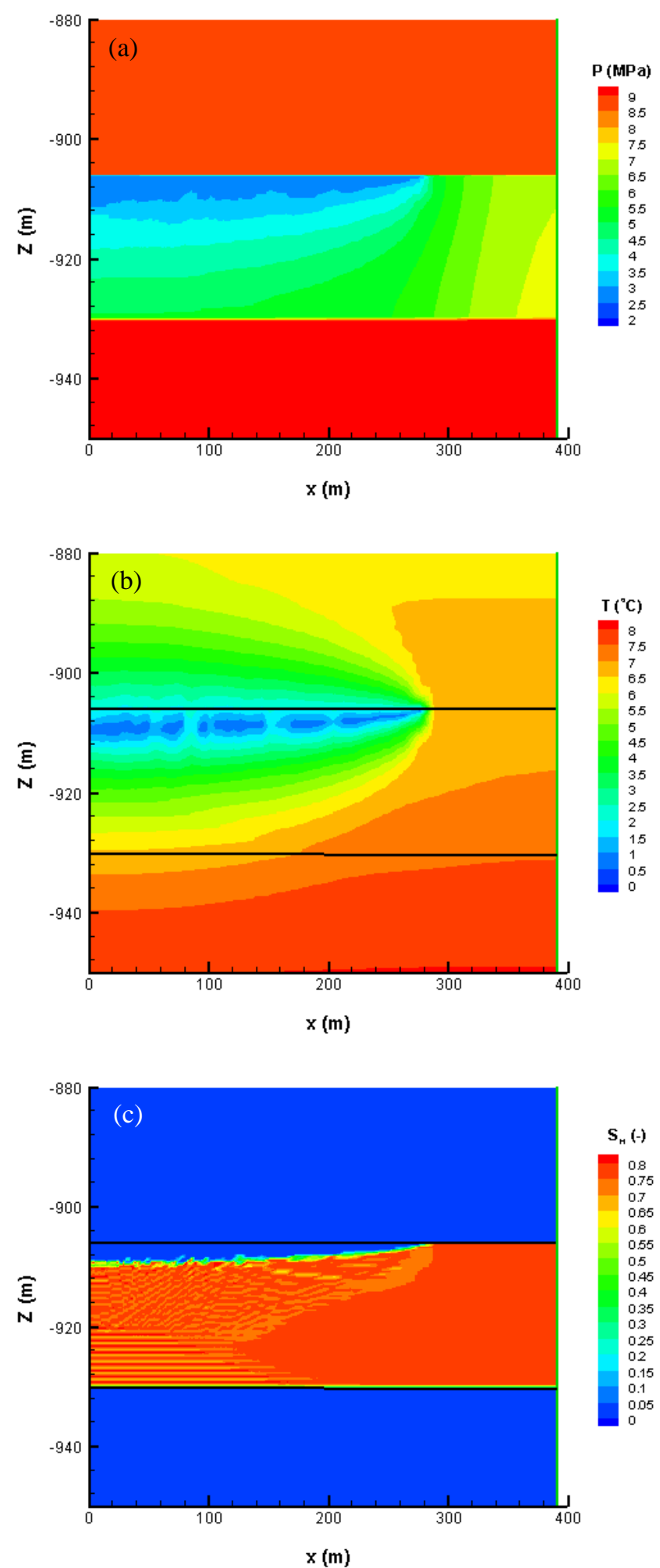

Figure 7. $P, T$, and $S_{H}$ distributions at $t=3 \mathrm{yrs}$ in the Mallik deposit 

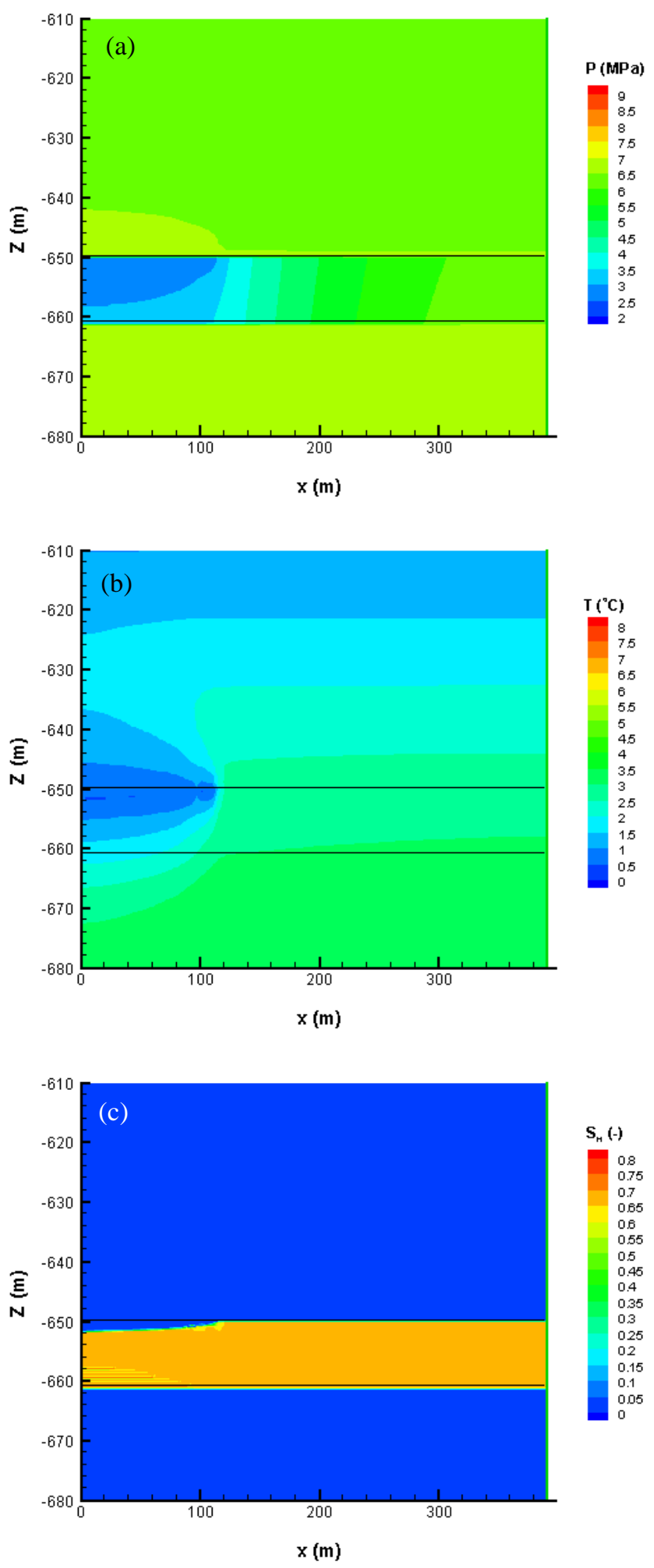

Figure 8. $P, T$, and $S_{H}$ distributions at $t=3 \mathrm{yrs}$ in the Mount Elbert and deposit. 


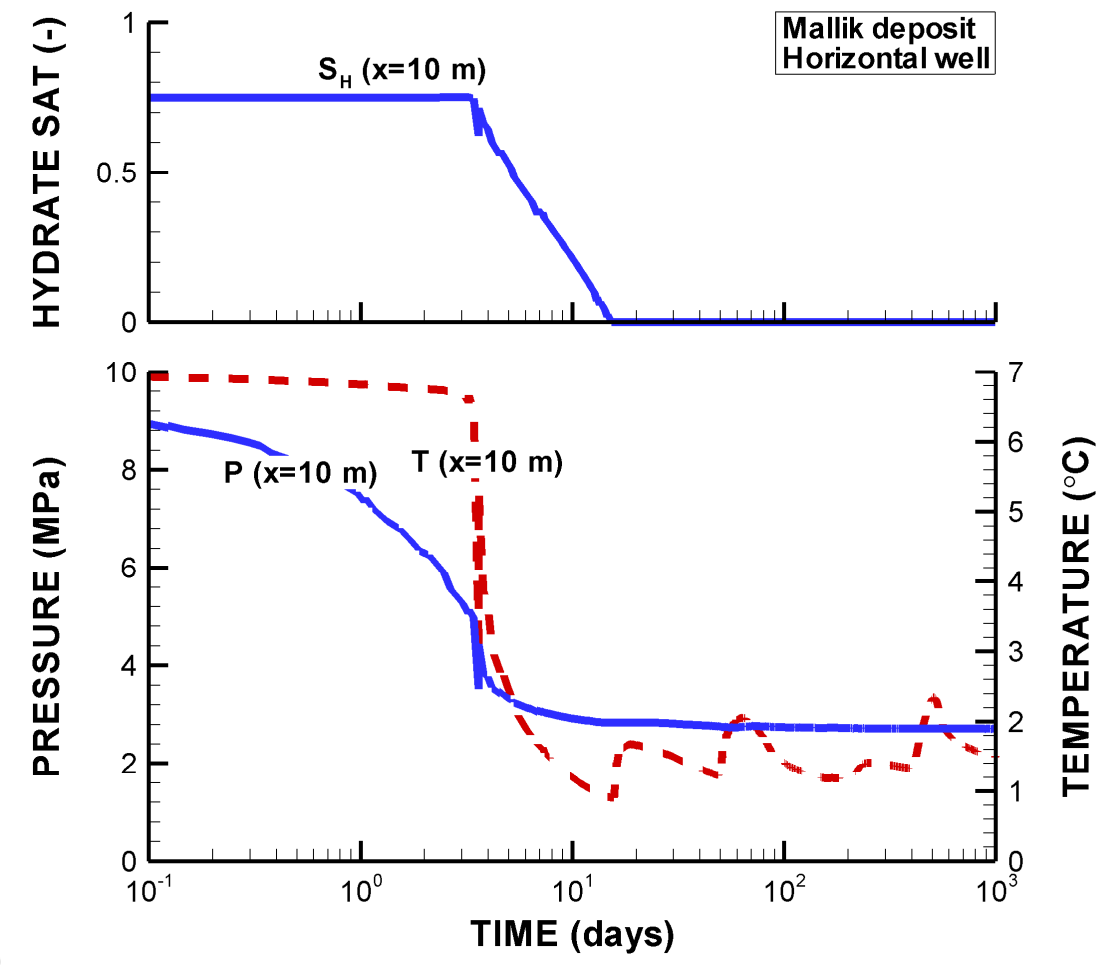

(a)
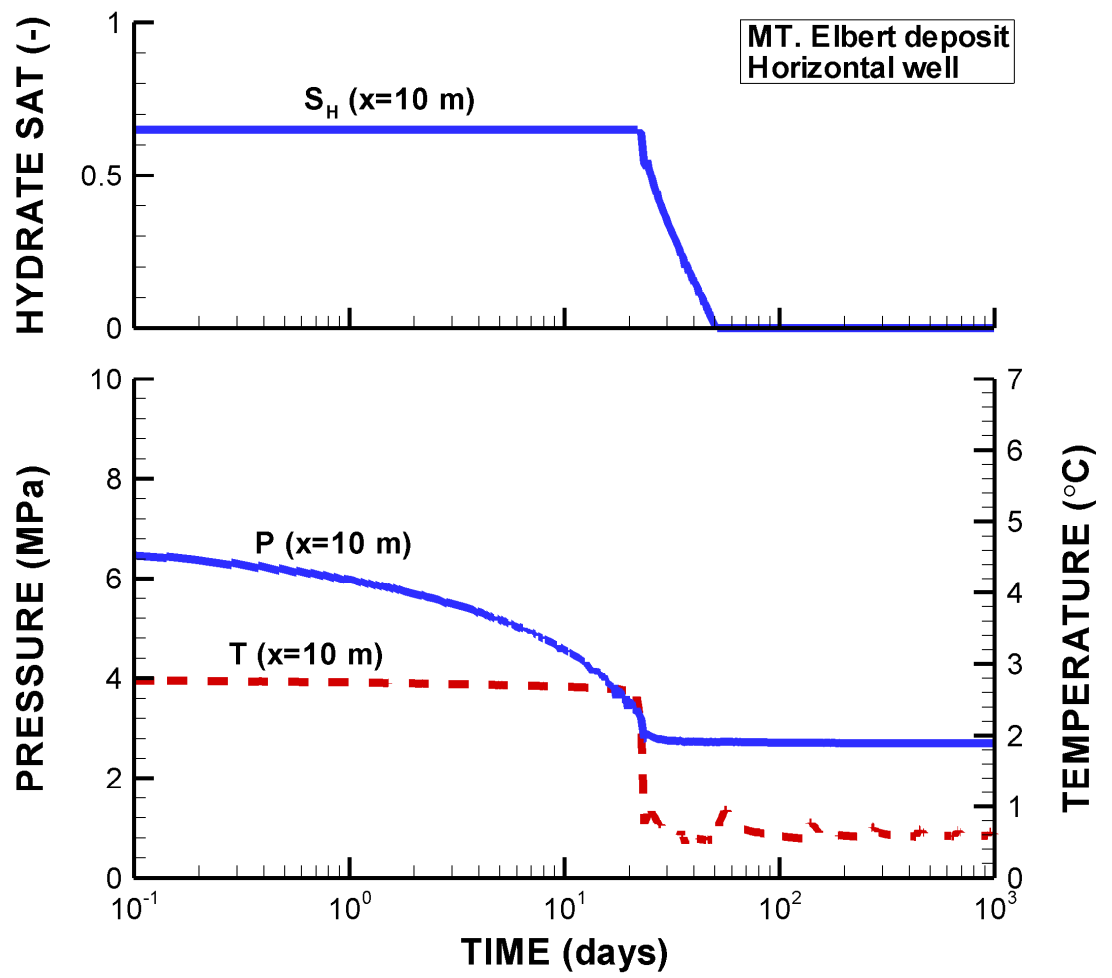

(b)

Figure 9. Evolution of $S_{H}, P$, and $T$ at the top of the HL of the two deposits at $x=10 \mathrm{~m}$. 


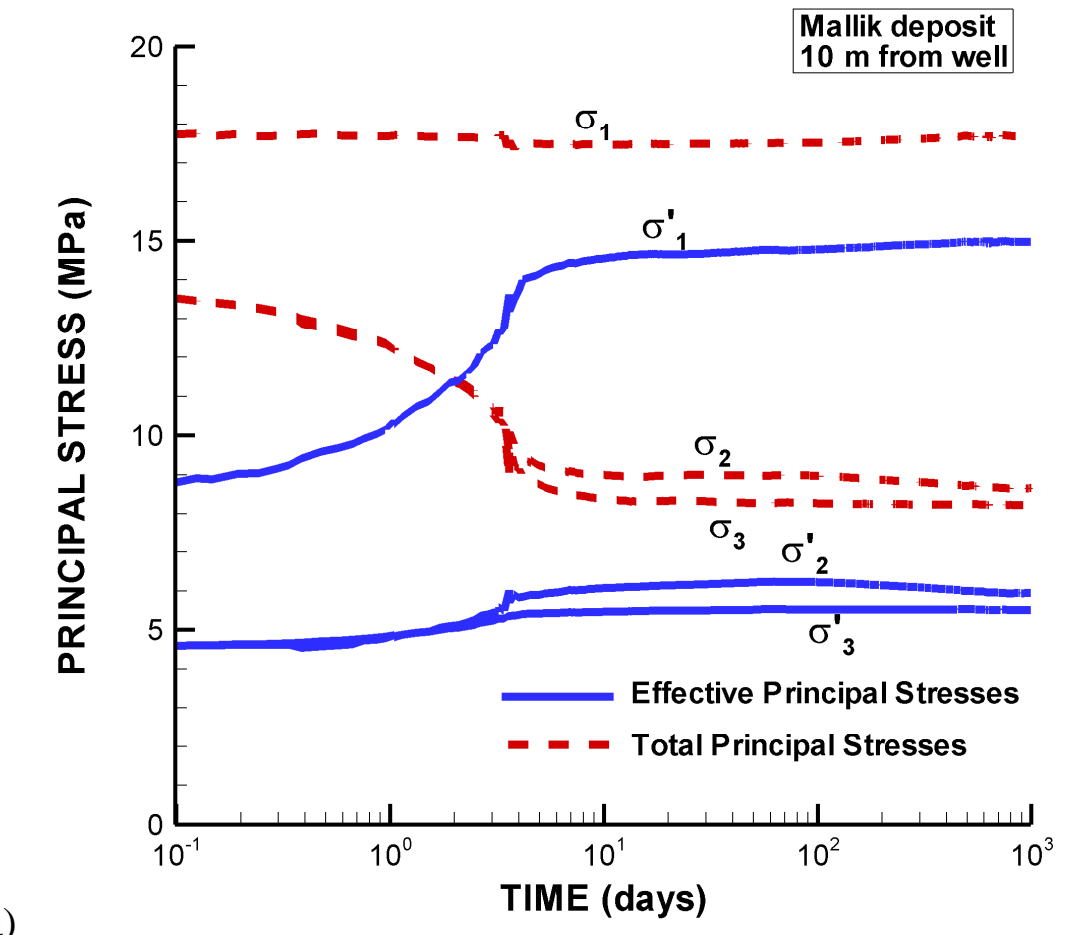

(a)

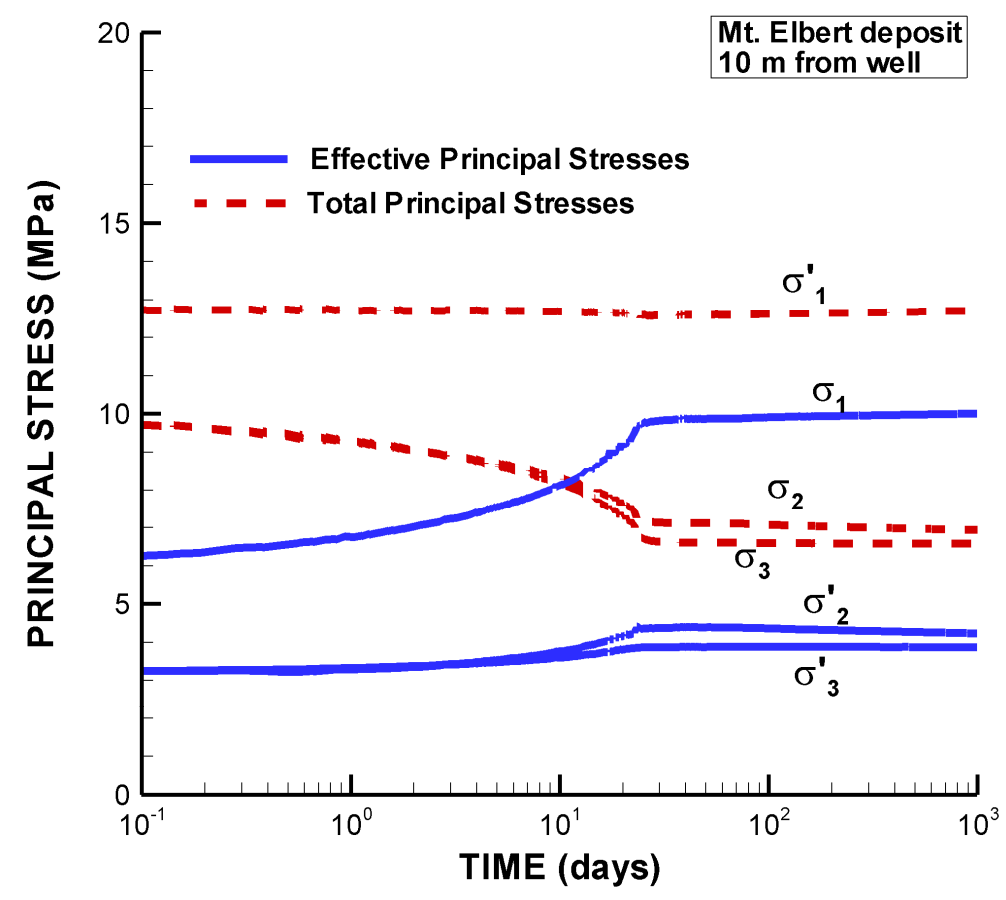

(b)

Figure 10. Principal stresses (effective and total) at the top of the HL of the two deposits at $x$ $=10 \mathrm{~m}$. 


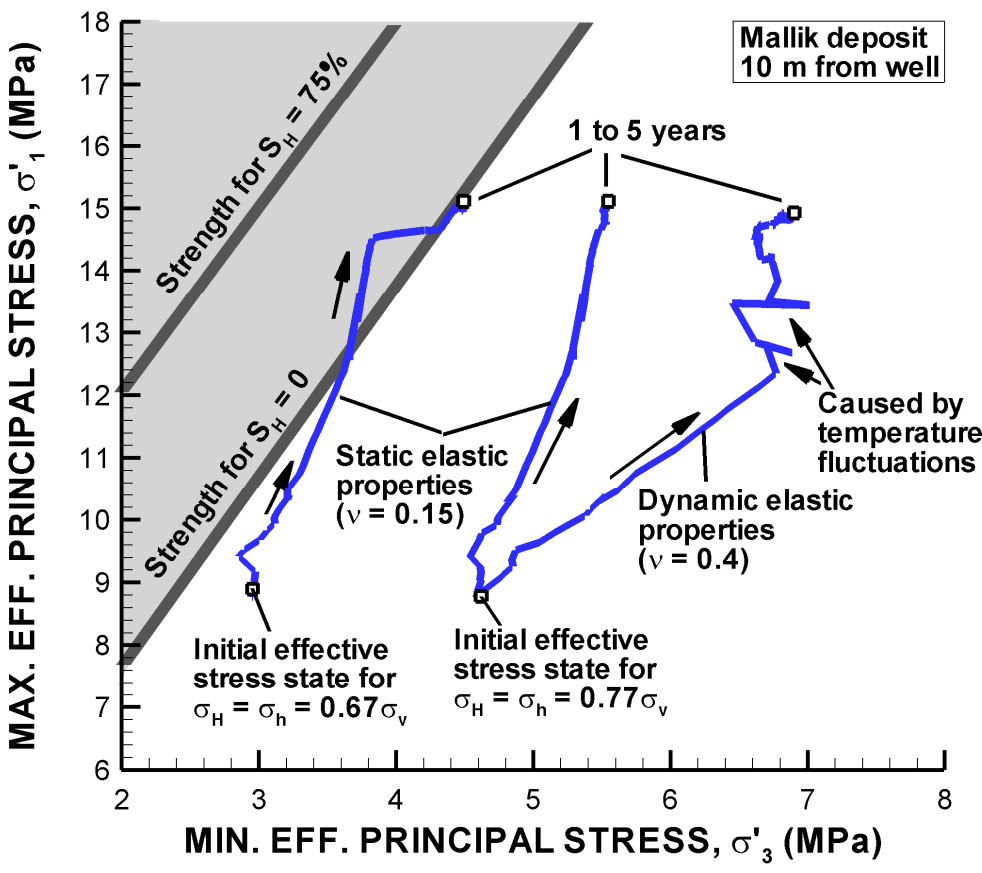

(a)

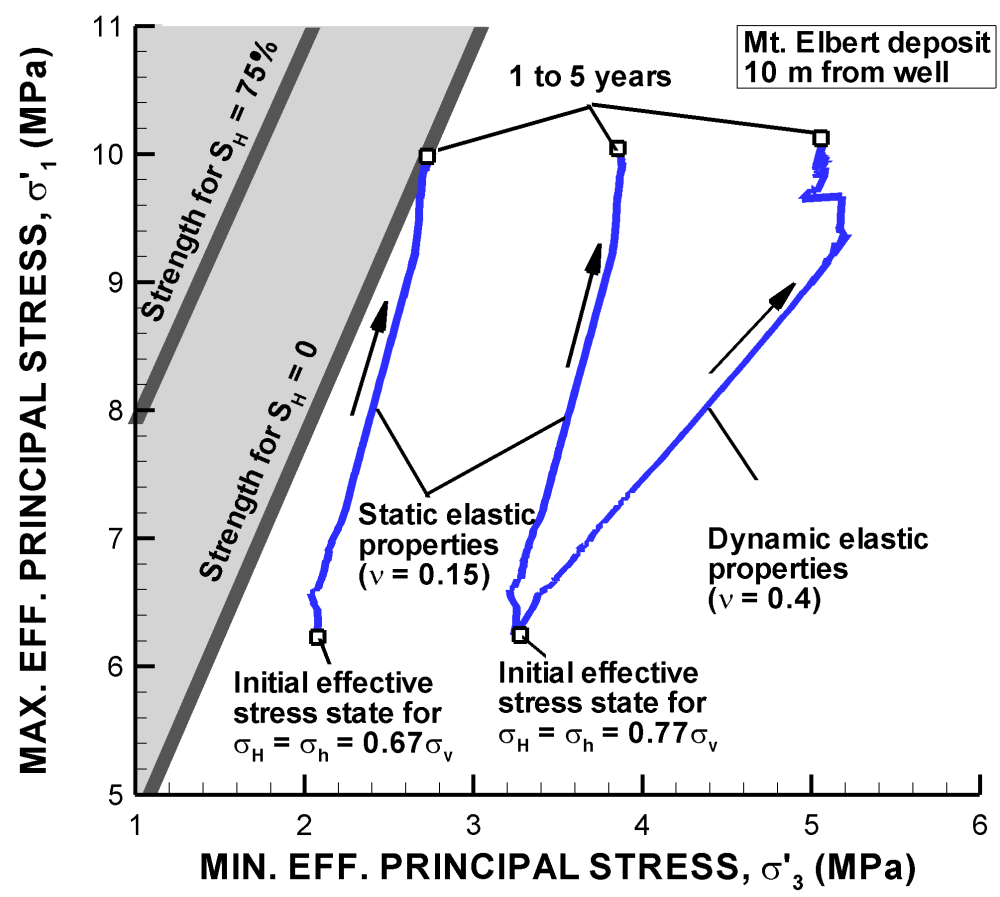

Figure 11. Path of reservoir stress state $\left(\sigma_{1}^{\prime}\right.$ vs. $\left.\sigma_{3}^{\prime}\right)$ for three different cases of mechanical parameters at the (a) Mallik and (b) Mount Elbert deposits. 


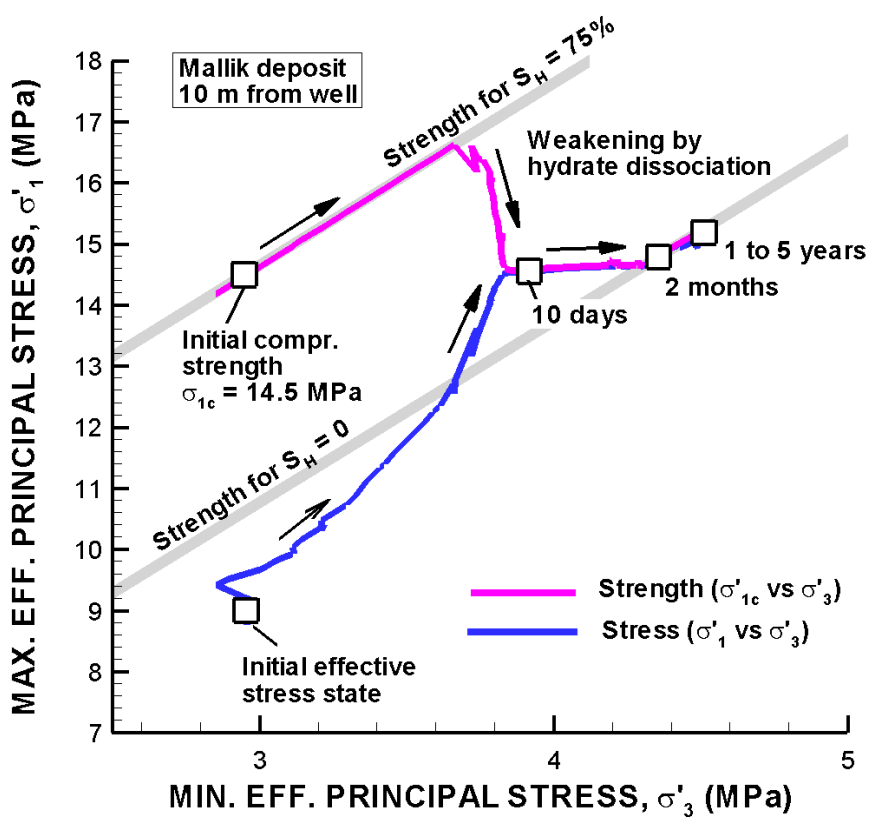

(a)

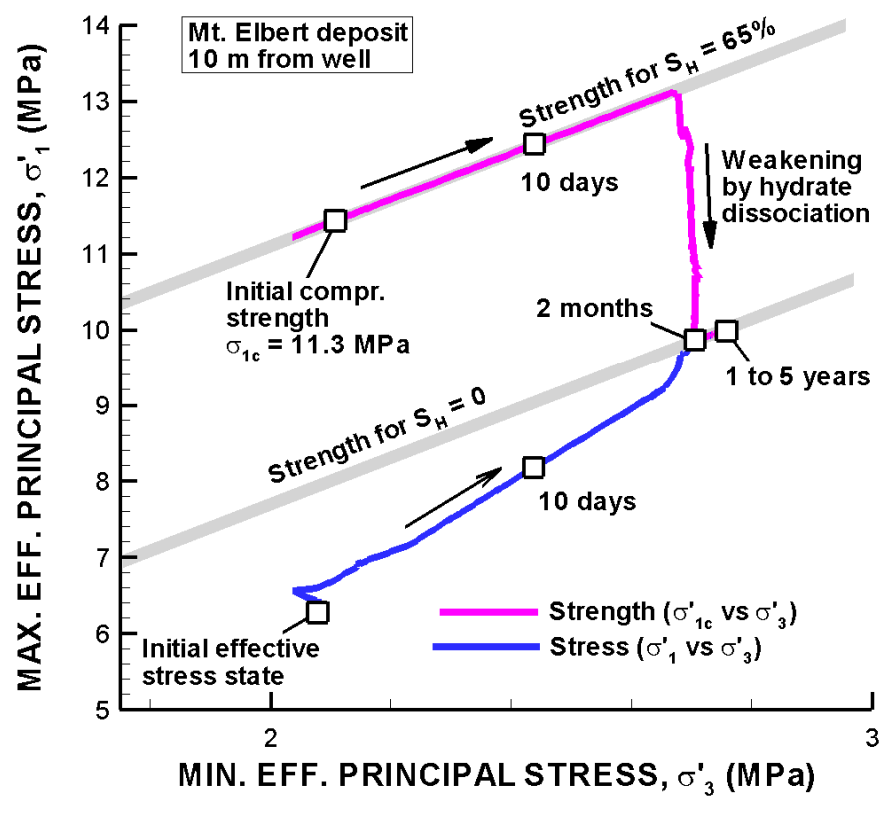

Figure 12. Path of reservoir stress state ( $\sigma_{1}^{\prime}$ vs. $\left.\sigma_{3}^{\prime}\right)$ and compressive strength $\left(\sigma_{1 C}^{\prime}\right.$ vs. $\left.\sigma_{3}^{\prime}\right)$ at point at the HL top and $x=10 \mathrm{~m}$. 


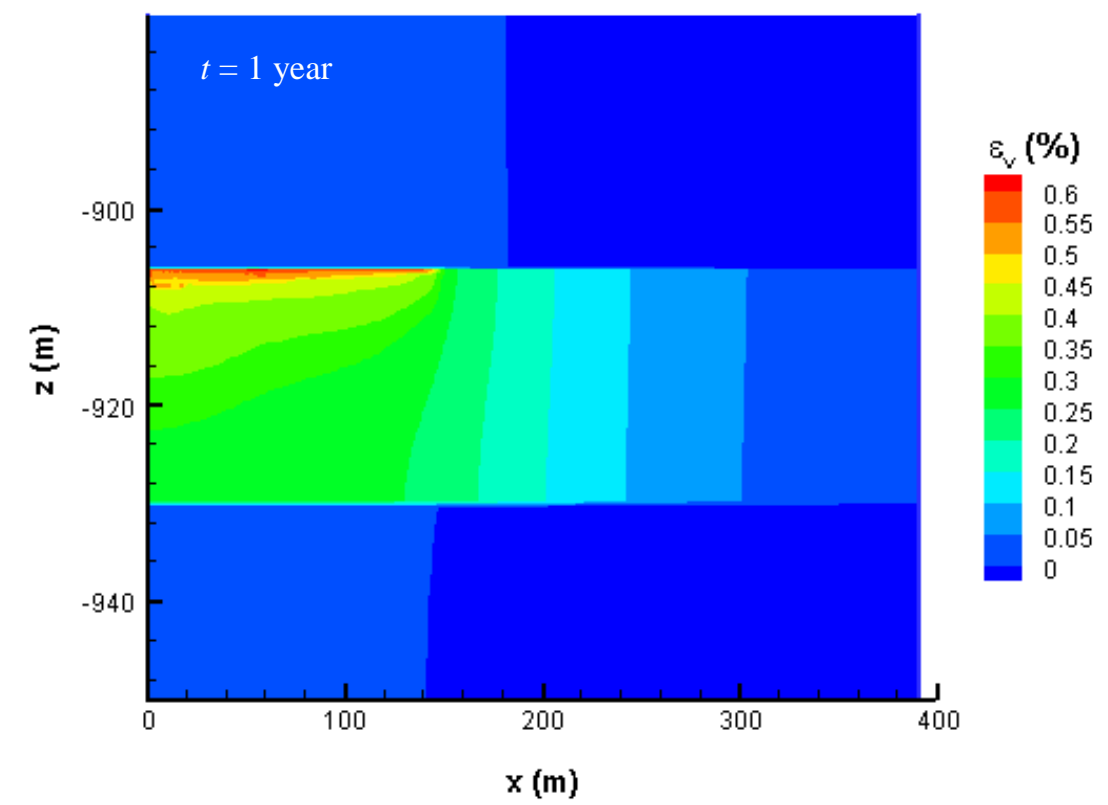

(a)

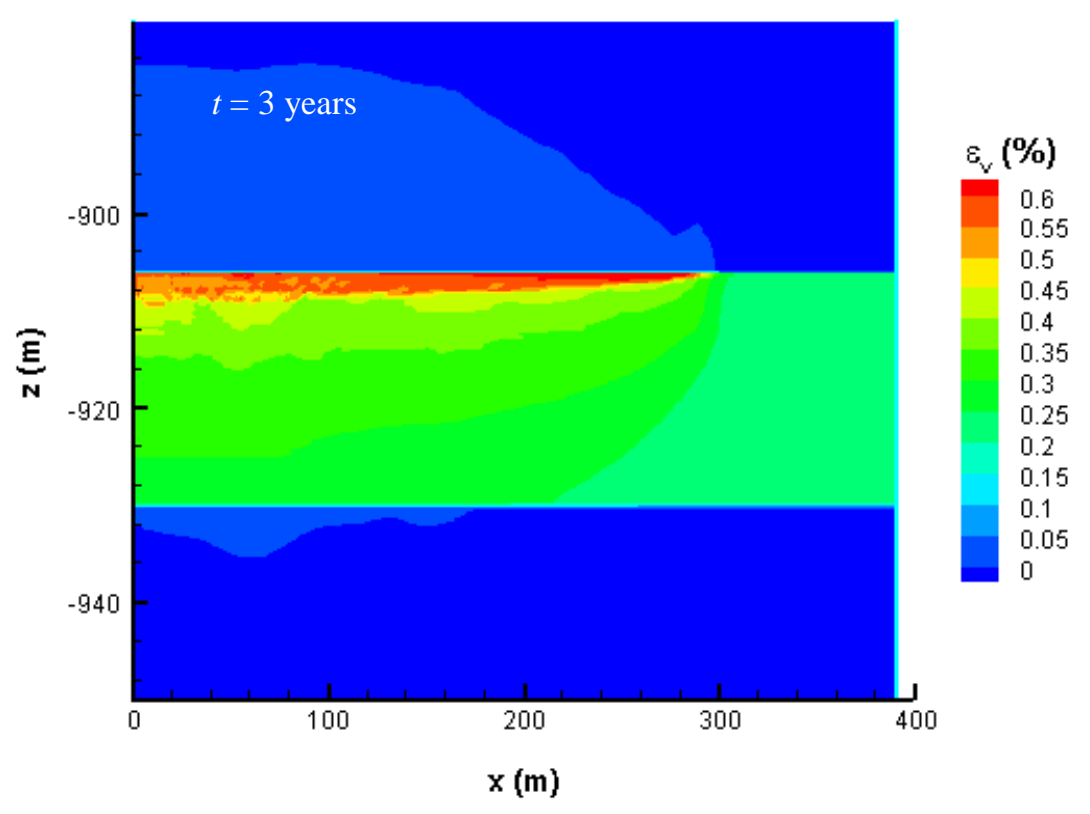

Figure 13. Distribution of volumetric strain $\varepsilon_{V}$ in the Mallik deposit at (a) $t=1 \mathrm{yr}$ and (b) $t=3$ yrs. 


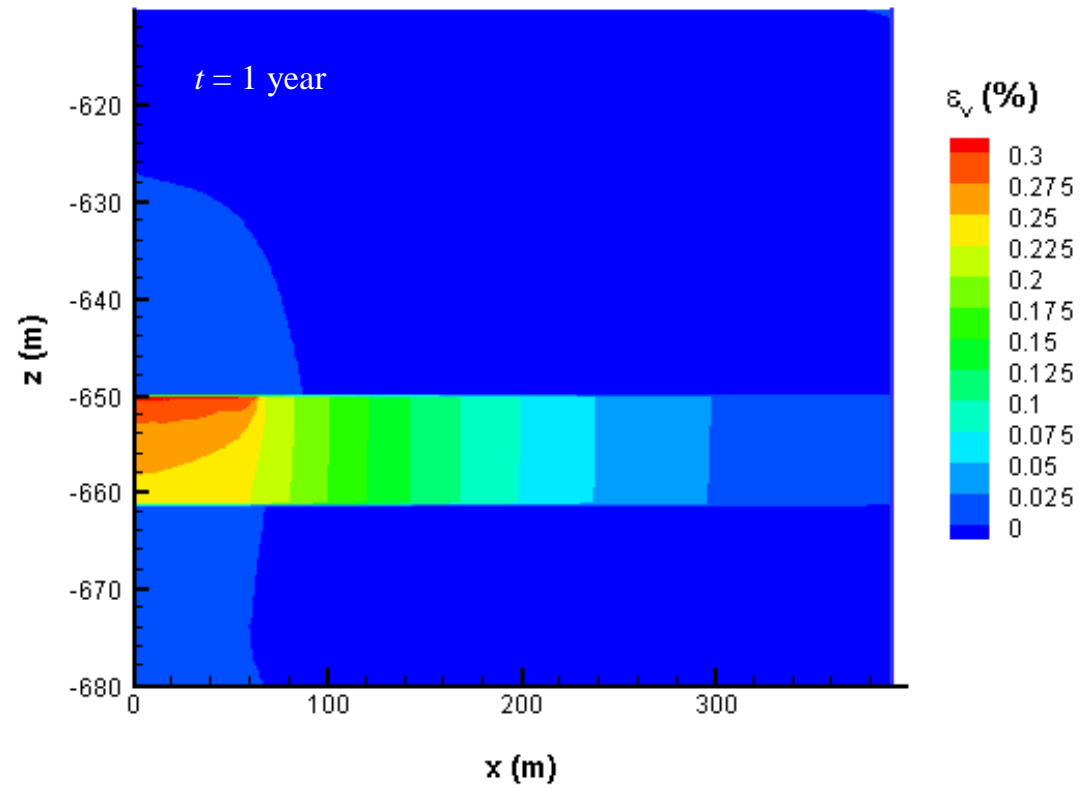

(a)

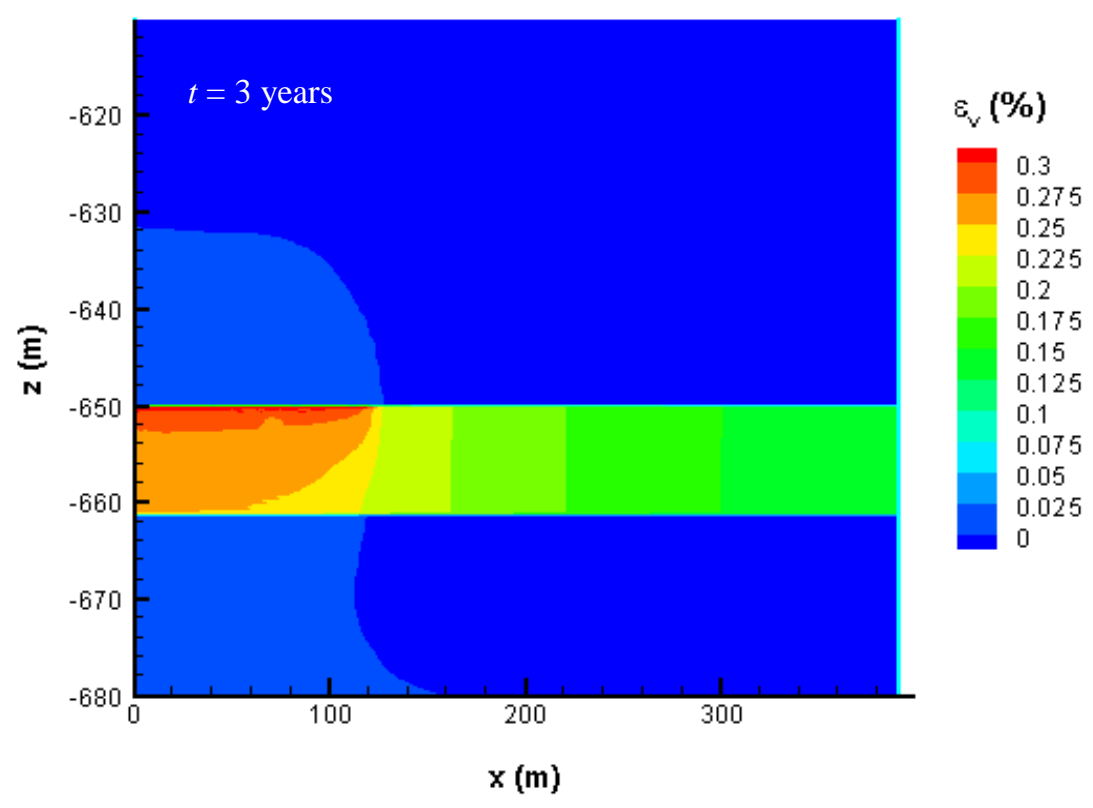

Figure 14. Distribution of volumetric strain $\varepsilon_{V}$ in the Mount Elbert deposit at (a) $t=1 \mathrm{yr}$ and (b) $t=3 \mathrm{yrs}$. 


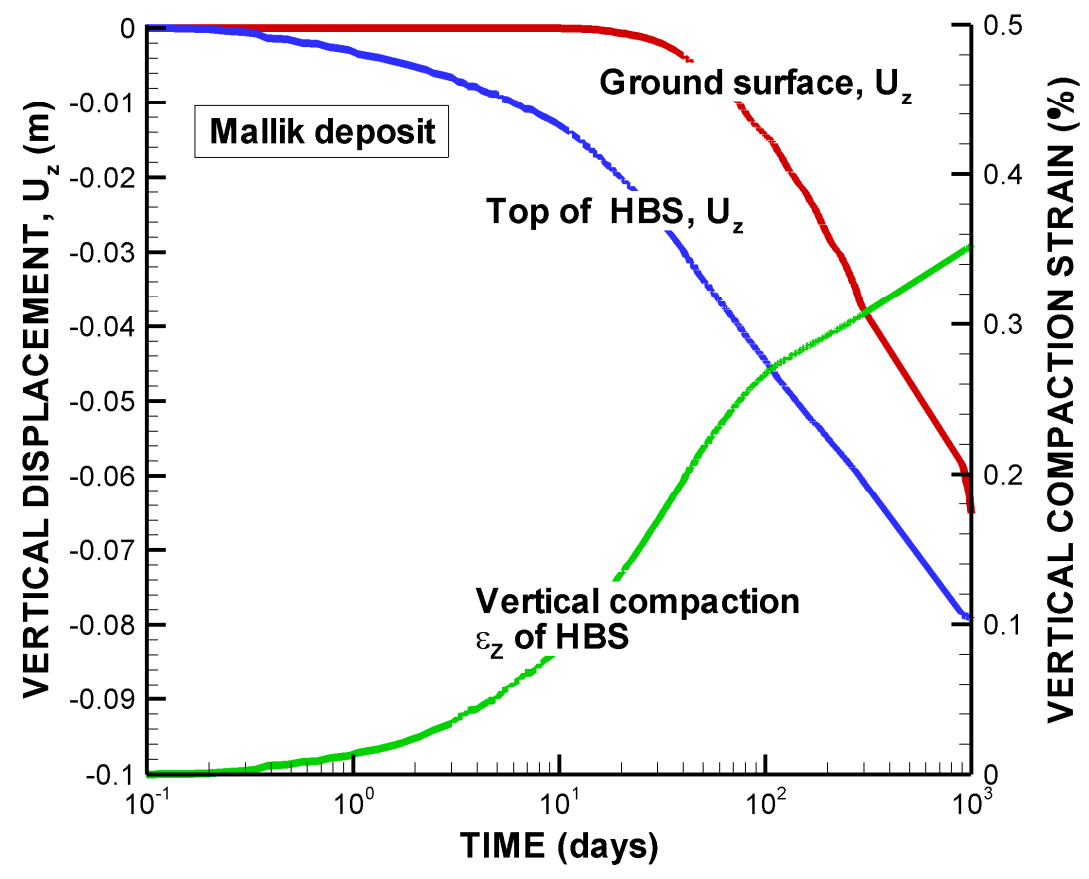

(a)

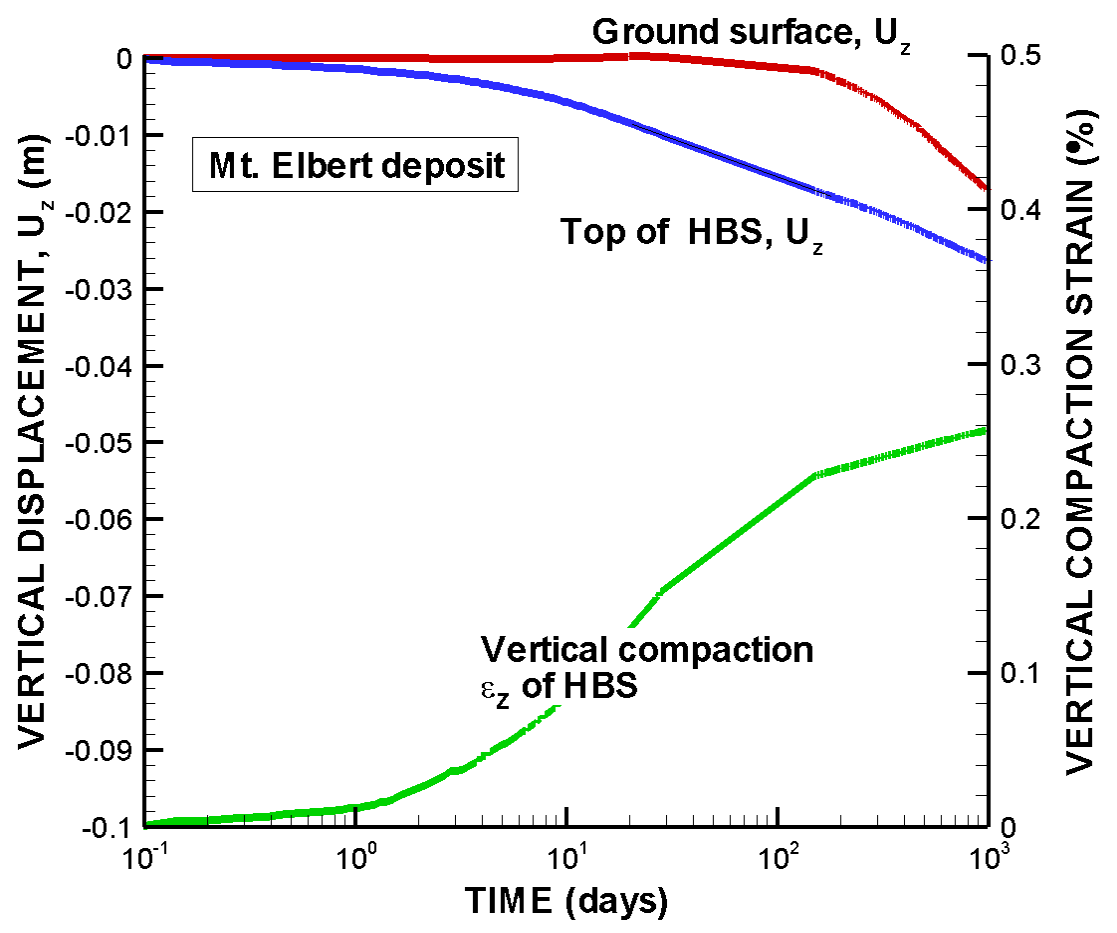

Figure 15. Evolution of $U_{Z}$ at the ground surface and at the HL top, and of the HBS $\varepsilon_{Z}$ at the (a) Mallik and (b) Mount Elbert deposits. 